The morphology, evolution and seismic visibility of partial melt at the core-mantle boundary: Implications for ULVZs

Juliane Dannberg ${ }^{1}$, Robert Myhill ${ }^{2}$, René Gassmöller ${ }^{1}$, Sanne Cottaar ${ }^{3}$

${ }^{1}$ Department of Geological Sciences, University of Florida, Gainesville, USA. E-mail:

juliane.dannberg@ufl.edu

${ }^{2}$ School of Earth Sciences, University of Bristol, Bristol, UK

${ }^{3}$ Department of Earth Sciences, University of Cambridge, Cambridge, UK

This is a pre-copyedited, author-produced PDF of an article accepted for publication in Geophysical Journal International following peer review. The version of record Dannberg, J., Myhill, R., Gassmöller, R., \& Cottaar, S. (2021). The morphology, evolution and seismic visibility of partial melt at the core-mantle boundary: Implications for ULVZs is available online at: https://doi.org/10.1093/gji/ggab242. 


\title{
The morphology, evolution and seismic visibility of partial melt at the core-mantle boundary: Implications for ULVZs
}

\author{
Juliane Dannberg ${ }^{1}$, Robert Myhill ${ }^{2}$, René Gassmöller ${ }^{1}$, Sanne Cottaar ${ }^{3}$ \\ ${ }^{1}$ Department of Geological Sciences, University of Florida, Gainesville, USA. E-mail: juliane.dannberg@ufl.edu \\ ${ }^{2}$ School of Earth Sciences, University of Bristol, Bristol, UK \\ ${ }^{3}$ Department of Earth Sciences, University of Cambridge, Cambridge, UK
}

\section{SUMMARY}

Seismic observations indicate that the lowermost mantle above the core-mantle boundary is strongly heterogeneous. Body waves reveal a variety of ultra-low velocity zones (ULVZs), which extend not more than $100 \mathrm{~km}$ above the core-mantle boundary and have shear velocity reductions of up to $30 \%$. While the nature and origin of these ULVZs remain uncertain, some have suggested they are evidence of partial melting at the base of mantle plumes. Here we use coupled geodynamic/thermodynamic modelling to explore the hypothesis that present-day deep mantle melting creates ULVZs and introduces compositional heterogeneity in the mantle. Our models explore the generation and migration of melt in a deforming and compacting host rock at the base of a plume in the lowermost mantle. We test whether the balance of gravitational and viscous forces can generate partially molten zones that are consistent with the seismic observations. We find that for a wide range of plausible melt densities, permeabilities and viscosities, lower mantle melt is too dense to be stirred into convective flow and instead sinks down to form a completely molten layer, which is inconsistent with observations of ULVZs. Only if melt is less dense

or at most ca. $1 \%$ more dense than the solid, or if melt pockets are trapped within the solid, can melt remain suspended in the partial melt zone. In these cases, seismic ve- 
locities would be reduced in a cone at the base of the plume. Generally, we find partial melt alone does not explain the observed ULVZ morphologies and solid-state compositional variation is required to explain the anomalies. Our findings provide a framework for testing whether seismically observed ULVZ shapes are consistent with a partial melt origin, which is an important step towards constraining the nature of the heterogeneities in the lowermost mantle and their influence on the thermal, compositional, and dynamical evolution of the Earth.

Key words: Structure of the Earth, Composition and structure of the mantle, Numerical modelling, Magma genesis and partial melting, Mantle processes

\section{INTRODUCTION}

The boundary between the core and the mantle represents a major compositional and mechanical barrier within the Earth. The interface is at a pressure of around $135 \mathrm{GPa}$, where the silicate mantle has a density of around $5800 \mathrm{~kg} / \mathrm{m}^{3}$ and the underlying metallic core has a density around $9900 \mathrm{~kg} / \mathrm{m}^{3}$ (Dziewonski \& Anderson, 1981). The liquid outer core has a viscosity on the order of $0.01 \mathrm{~Pa}$ s (Alfe et al., 2000), while the bulk of the lower mantle has a viscosity exceeding $10^{20} \mathrm{~Pa}$ s (Mitrovica \& Forte, 2004). The high viscosity of the lower mantle generates a thermal boundary layer at its base that is on the order of $100 \mathrm{~km}$ thick, and it has been suggested that the temperature changes by around 1000 K (500-1800 K) across this layer (Stacey \& Loper, 1983; Lay et al., 2008). This high thermal gradient is responsible for driving a signifieant part of mantle convection.

Tomographic inversions have revealed a multitude of seismic heterogeneities above the core mantle boundary (CMB), which include zones $10 \mathrm{~s}$ of kilometres thick and 100s-1000 km wide with very low shear velocities which lie on top of the CMB. These discontinuous zones are referred to as UltraLow Velocity Zones (ULVZs, Williams \& Garnero, 1996). The chemistry and temperature of these zones remains a mystery, but they are commonly associated with mantle upwelling (e.g. Jellinek \& Manga, 2004; McNamara et al., 2010; Yuan \& Romanowicz, 2017; Mundl-Petermeier et al., 2020).

Several seismic/studies have targeted regions of the CMB using seismic waves that reflect, refract, and diffract at the boundary, revealing the patchy nature of ULVZs (see compilation and review in Yu \& Garnero (2018), also Kim et al. (2020)). Seismic phases propagating through the ULVZ vertically (e.g. ScS, ScP) or horizontally (e.g. Sdiff, SPdKS) offer different constraints on their physical properties in terms of velocity reductions, height, lateral extent, and density of the ULVZs. A wide range of properties are published for ULVZs with shear wave velocity reductions varying from 15 to $30 \%, \mathrm{P}$ 
wave velocity reductions from 5 to $12 \%$, heights from 5 to $40 \mathrm{~km}$, and lateral extents from 100 to 900 $\mathrm{km}$. It is not yet known to what degree this spread in published properties reflects the true spread in ULVZ properties, considering the inherent uncertainties in imaging structures nearly $3000 \mathrm{~km}$ from the nearest station.

Potential hypotheses to explain the low velocities of ULVZs include enrichment in ferrous iron (Mao et al., 2006; Muir \& Brodholt, 2015; Liu et al., 2016; Wicks et al., 2017) and the presence of partial melt (Williams \& Garnero, 1996; Berryman, 2000; Kimura et al., 2017). These do not represent mutually exclusive end-member scenarios. Fractionation during partial melting of mantle compositions at $>100 \mathrm{GPa}$ forms dense, iron-enriched melts (Stixrude et al., 2009; Nomura et al., 2011; Tateno et al., 2014; Caracas et al., 2019). Separation of this melt from the residual mantle could form an iron-enriched layer at the base of the mantle. Thus, ULVZs today could represent present day melt or the frozen residue of a previously molten layer (Labrosse et al., 2007; Boukaré et al., 2015). Conversely, iron enrichment lowers melting temperatures (Boukaré et al., 2015) and raises the possibility that partial melting still occurs at CMB temperatures. Other chemical variations could further lower melting temperatures; for example, silica-saturated lithologies such as subducted mafic crust start melting at a lower temperature than ultramafic lithologies (Andrault et al., 2014; Baron et al., 2017). The presence of volatile components such as $\mathrm{H}_{2} \mathrm{O}$ and $\mathrm{CO}_{2}$ could also significantly reduce solidus temperatures (Sano et al., 2008).

To summarize the many conceptual models, it has variously been suggested that ULVZs are remnants of Earth's early differentiation (Labrosse et al. 2007), created from subducted material (Dobson \& Brodholt, 2005), products of core-mantle reaction (Knittle \& Jeanloz, 1989; Buffett et al., 2000), generated at the present day by the formation of silicate melts (Kimura et al., 2017) or metallic melts generated by redox reactions from peridotitic bulk compositions (Trønnes et al., 2019), or by exsolution of silicate melts out of the core (Helffrich et al., 2020). In this study, we explore the possibility that ULVZs are a manifestation of present-day deep mantle melting, investigating their dynamic stability over time frames of hundreds of millions of years, and the compositional heterogeneities created by this melting.

Several avenues have been taken to explore the role of partial melt in ULVZs. Partial melt has a larger influence on shear wave velocity than $\mathrm{P}$-wave velocity, resulting in high $\delta \mathrm{Vs}: \delta \mathrm{Vp}$ ratios (Williams \& Garnero, 1996; Berryman, 2000). However, constraining this ratio accurately is difficult as $\mathrm{P}$ /and $\mathrm{S}$ wave studies have different resolutions, and studies have argued both for and against the presence of partial melt e.g. (Thorne \& Garnero, 2004; Rost et al., 2005; Idehara, 2011; Hansen et al., 2020). A compilation of all seismic studies so far, which covers a fraction of the globe, suggests no correlation between the presence of ULVZs and the suspected hottest regions of the lowermost 
mantle (Yu \& Garnero, 2018). The largest mapped ULVZs, however, have been imaged at the potential roots of the Hawaiian (Cottaar \& Romanowicz, 2012), Icelandic (Yuan \& Romanowicz, 2017), Samoan (Thorne et al., 2013), Marquesas (Kim et al., 2020), and Galapagos (Cottaar \& Li, 2019) mantle plumes, which supports a correlation between ULVZ presence and zones of convergence at the base of the mantle. Three of these ULVZs are well approximated by a wide cylindrical shape, consistent with an axisymmetric temperature anomaly which might be expected of a plume and the presence of partial melt (Yuan \& Romanowicz, 2017). While seismic studies continue to invoke partial melt as a potential cause for the ultra-low shear velocities, dynamical models have questioned if partial melt can create ULVZ-like morphological features (Hernlund \& Tackley, 2007; Hernlund \& Jellinek, 2010).

Most studies explore the dynamics and expected morphologies of compositionally distinct ULVZs without considering partial melting (McNamara et al., 2010; Bower et al., 2011; Hier-Majumder \& Drombosky, 2016; Li et al., 2017; Hernlund \& Bonati, 2019). Including partial melt and melt migration in geodynamical models is non-trivial, as the dynamics of the melt need to be resolved on finer scales and over smaller time steps (Dannberg \& Heister, 2016; Dannberg et al., 2019). An early model by Okamoto et al. (2005) investigated the effects of partial melting on seismic anisotropy, assuming melt is neutrally buoyant (so that liquid and solid do not separate gravitationally, which avoids some of the physical and computational complexity). Since then, both experiments (Ohtani et al., 2001; Sakamaki et al., 2006; Mosenfelder et al., 2009; Nomura et al., 2011) and theoretical calculations (Caracas et al., 2019) have indicated that iron fractionation between silicate melt and solid might create melts denser than their residues at high pressures and temperatures. Hier-Majumder (2014) include gravitational separation of melt and solid to model how compaction forces redistribute melt in a partially molten layer along a 1-D profile. Hernlund \& Tackley (2007) illustrate the tendency of dense melts to form a layer at the CMB. Hernlund \& Jellinek (2010) expand on this model by exploring a potential role for surrounding mantle stirring to retain a two-phase mixed or mushy zone. However, these models do not include a full coupling of a deforming and compacting solid mantle, melt migration, and a thermodynamic model of mantle mélting.

Recently, a solver for coupled mantle and magma dynamics was implemented in the Advanced Solver for Problems in Earth's Convection (ASPECT) and applied to melt dynamics in a rising mantle plume (Dannberg \& Heister, 2016) and beneath mid-ocean ridges (Dannberg et al., 2019). Here we apply this tool to model the base of a plume at the $\mathrm{CMB}$, and implement a melting model based on a thermodynamic parametrization for solid-liquid silicates at high pressures and temperatures (Boukaré et al., 2015). We explore the effects of varying the permeability of lowermost mantle rocks, viscosity of the solids and melts, melting temperature, and density contrast between melt and solid. Exploring a wide parameter space allows us to map out the possible dynamics of partially molten material close to 
the CMB, and to assess under which conditions it would form structures similar to observed ULVZs. We assess the consistency between the models and seismic observations of ULVZs by estimating their seismic velocity signatures, and discuss the predicted range of plume compositions.

\section{METHODS}

In order to predict the shape and stability of partially molten regions in the lowermost mantle, the amount and distribution of melt present in these regions, and the spatial distribution of their chemical composition, we need to model several interconnected processes. These include

(i) the evolution of composition and temperature of material as it enters the lowermost mantle, moves through partially molten regions, and ascends in mantle plumes,

(ii) the melting of material as it is heated up upon approaching the $\mathrm{CMB}$, and the associated changes in major element composition in both solid and melt,

(iii) the flow of melt, driven both by its different density compared to the solid, and deformation of the solid rock and the associated dynamic pressure,

(iv) the freezing of melt and the associated changes in chemical composition in both solid and melt as material rises and cools and temperatures fall below the solidus

Consequently, we need to combine a solver for the magma/mantle dynamics equations (Section 2.1), a thermodynamic model for melting and freezing of rocks in the lowermost mantle that efficiently computes the fractions and compositions of coexisting solid and melt for a given temperature, pressure and bulk composition (Sections 2.2 and 2.3), and equations of state (Appendix C) that provide the solid and melt densities needed to compute the buoyancy force. In addition, we need a conversion from the outputs of the geodynamic models (porosity, temperature, pressure, composition) to seismic properties of the lowermost mantle (Section 2.4) so that we can compare our predictions to seismologic observations. An overview of our workflow that shows how geodynamic and thermodynamic modeling are intertwined is given in Figure 1.

Our work builds on previous studies linking geodynamic and thermodynamic models. Some examples of studies that illustrate useful concepts are given in the following: For general considerations and the development of a theoretical framework, we refer the reader to Rudge et al. (2011) and Keller \& Suckale (2019). A workflow for integrating a thermodynamic model in the form of a phase diagram for a two-component system under the assumption of chemical phase equilibrium is outlined in Katz (2008). The development and application of a framework for reactive, disequilibrium, multicomponent melting coupled to two-phase flow is presented in Keller \& Katz (2016). 


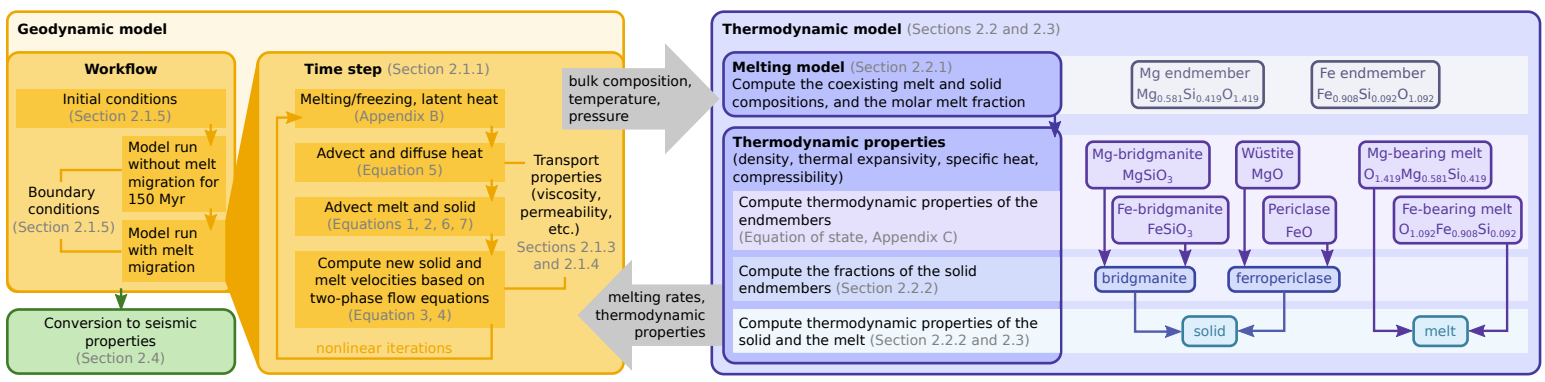

Figure 1. Workflow of coupling geodynamic and thermodynamic models.

\subsection{Geodynamic modeling}

To create the geodynamic models for this study, we use the mantle convection code ASPECT (Heister et al., 2017; Bangerth et al., 2019), which includes a solver for coupled magma/mantle dynamics (Dannberg \& Heister, 2016; Dannberg et al., 2019), involving the interaction between a solid, deforming, compacting and expanding host rock, and a (fluid) melt phase that flows though the pores of the rock. To model the transition between solid and molten material, we have implemented a thermodynamic model in ASPECT, including both a parametrization of the melting process and an equation of state, that will be described in Sections 2.2 and 2.3.

\subsubsection{Governing equations}

Specifically, we consider the equations describing the behaviour of silicate melt percolating through and interacting with a viscously deforming host rock (é.g. (McKenzie, 1984)):

$$
\begin{aligned}
\frac{\partial}{\partial t}\left[\rho_{f} \phi\right]+\nabla \cdot\left[\rho_{f} \phi \mathbf{u}_{f}\right] & =\Gamma, \\
\frac{\partial}{\partial t}\left[\rho_{s}(1-\phi)\right]+\nabla \cdot\left[\rho_{s}(1-\phi) \mathbf{u}_{s}\right] & =-\Gamma, \\
\phi\left(\mathbf{u}_{f}-\mathbf{u}_{s}\right) & =-\frac{k_{\phi}}{\eta_{f}}\left(\nabla P_{f}-\rho_{f} \mathbf{g}\right), \\
-\nabla \cdot\left[2 \eta \dot{\varepsilon}+\xi\left(\nabla \cdot \mathbf{u}_{s}\right) \mathbf{1}\right]+\nabla P_{f} & =\bar{\rho} \mathbf{g} .
\end{aligned}
$$

Here, $\phi$ is the porosity, $\rho$ is the density, $\mathbf{u}$ is the velocity, $\Gamma$ is the melting rate, $k_{\phi}$ is the permeability, $\eta_{f}$ is the melt viscosity, $P$ is the pressure, $\mathrm{g}$ is the gravity vector, $\eta$ is the shear viscosity in the two-phase mixture, $\xi$ is the bulk viscosity, $\dot{\varepsilon}=\nabla \mathbf{u}_{s}+\left(\nabla \mathbf{u}_{s}\right)^{T}-\frac{1}{3}\left(\nabla \cdot \mathbf{u}_{s}\right) \mathbf{1}$ is the deviatoric strain rate, and 1 is the unit tensor. The index $f$ indicates the melt (fluid), the index $s$ indicates the solid, and quantities that are phase-weighted averages between the solid and the fluid are denoted by 
bars. The melting rate is computed in the thermodynamic model (see Section 2.2.1 and Appendix B1, Equation B.1).

In addition to the mechanical description of the problem, we solve an equation for energy conservation that includes shear heating, adiabatic heating, and release and consumption of latent heat of melting/freezing (adapted from Rudge et al., 2011):

$$
\begin{aligned}
& \phi \rho_{f} C_{P}\left(\frac{\partial T}{\partial t}+\mathbf{u}_{f} \cdot \nabla T\right)+(1-\phi) \rho_{s} C_{P}\left(\frac{\partial T}{\partial t}+\mathbf{u}_{s} \cdot \nabla T\right)-\nabla \cdot k \nabla T \\
= & 2 \eta(\dot{\varepsilon}: \dot{\varepsilon})+\xi\left(\nabla \cdot \mathbf{u}_{s}\right)^{2}+\frac{\phi^{2} \eta_{f}}{k_{\phi}}\left(\mathbf{u}_{f}-\mathbf{u}_{s}\right)^{2} \\
& +\alpha T\left(\phi \rho_{f} \mathbf{u}_{f} \cdot \mathbf{g}+(1-\phi) \rho_{s} \mathbf{u}_{s} \cdot \mathbf{g}\right) \\
& +\Delta \mathcal{H} \Gamma
\end{aligned}
$$

$C_{P}$ is the specific heat capacity, $T$ is temperature, $k$ is the thermal conductivity $\alpha$ is the thermal expansivity and $\Delta \mathcal{H}$ is the enthalpy of fusion and controls the release of latent heat upon melting/freezing (see Section 2.2.1). The thermodynamic properties $\alpha, \beta_{T}, C_{P}$ and $\alpha$ for the solid and melt are computed using the "Modified Tait" equation of state (Holland \& Powell, 2011) and ideal mixing models as described in Section 2.2.2 and Appendix C. The resulting densities of the solid and melt are shown in Section 2.2, while alterations to the densities in our models are déscribed in Section 2.3.

This gives us a nonlinear system of equations to solve for the temperature $T$, porosity $\phi$, pressure $P$ in the solid and the melt, and the solid velocity. The melt velocity can then be computed using equation (3). In ASPECT, we use a fixed-point iteration scheme to solve this nonlinear system, which typically converges within a few nonlinear iterations.

\subsubsection{Tracking chemical composition}

Because melting and freezing change the composition of both the solid rock and the melt, we also have to track the chemical composition of both phases. In order to do that, we solve the advection equations

$$
\begin{gathered}
\frac{\partial C_{s}}{\partial t}+\mathbf{u}_{s} \cdot \nabla C_{s}=\Gamma^{s} \\
\frac{\partial C_{f}}{\partial t}+\mathbf{u}_{f} \cdot \nabla C_{f}=\Gamma^{f} .
\end{gathered}
$$

In these expressions, the compositions $C_{s}$ and $C_{f}$ represent the molar fraction of the iron-bearing endmember in the binary melting model, as given in Table 2 . To relate these quantities to chemical composition, the molar concentration $x_{i}$ of each component $i\left(i=\mathrm{MgO}, \mathrm{FeO}\right.$ or $\left.\mathrm{SiO}_{2}\right)$ in the solid or 
melt at any value of $C_{s}$ or $C_{f}$ can be calculated from

$$
\begin{aligned}
& x_{i, \text { solid }}=\left(1-C_{s}\right) x_{i, \mathrm{Mg}-\mathrm{mbr}}+C_{s} x_{i, \mathrm{Fe}-\mathrm{mbr}} \\
& x_{i, \mathrm{melt}}=\left(1-C_{f}\right) x_{i, \mathrm{Mg}-\mathrm{mbr}}+C_{f} x_{i, \mathrm{Fe}-\mathrm{mbr}}
\end{aligned}
$$

where $x_{i, \mathrm{Mg} \text {-mbr }}$ and $x_{i, \mathrm{Fe}-\mathrm{mbr}}$ are the molar concentrations of component $i$ in the $\mathrm{Mg}$-bearing and $\mathrm{Fe}$ bearing endmember. We compute the melting rate $\Gamma$ and the changes in melt and solid composition, $\Gamma^{f}$ and $\Gamma^{s}$ using the melting parametrization described in Section 2.2.1. Note that while $\Gamma$ is a rate of mass exchange, $\Gamma^{s}$ and $\Gamma^{f}$ are rates of molar chemical exchange. Solving the system of equations (1)-(7) provides the pressure, temperature, bulk composition of the rock and the current melt volume fraction (the porosity $\phi$ ) at each point in the model. The melting parametrization allows us to use this information to compute the equilibrium melt fraction $F$ for these conditions. Since $F$ needs to be computed several times in every time step, and for every point in the model domain where we compute the solution to equations (6)-(7), it is important that the melting parametrization can be evaluated quickly (see Section 2.2.1). We discuss the numerical methods we use to address the nonlinear coupling between equations (1), (2), (6) and (7) in Appendix B1.

\subsubsection{Rheology}

We choose a rheology that depends both on temperature and melt fraction such that

$$
\begin{gathered}
\eta= \begin{cases}(1-\phi) \eta_{0} \exp \left(-\alpha_{\phi} \phi\right) \exp \left(-b \frac{T-T_{\mathrm{adi}}}{T_{\mathrm{adi}}}\right), & \phi<\phi_{\max } \\
\left(1-\phi_{\max }\right) \eta_{0} \exp \left(-\alpha_{\phi} \phi_{\max }\right) \exp \left(-b \frac{T-T_{\mathrm{adi}}}{T_{\mathrm{adi}}}\right), & \phi \geq \phi_{\max }\end{cases} \\
\xi= \begin{cases}(1-\phi) \frac{\xi_{0}}{\phi_{\min }} \exp \left(-b \frac{T-T_{\mathrm{adi}}}{T_{\text {adi }}}\right), & \phi<\phi_{\min } \\
(1-\phi) \frac{\xi_{0}}{\phi} \exp \left(-b \frac{T-T_{\mathrm{adi}}}{T_{\mathrm{adi}}}\right), & \phi_{\min } \leq \phi<\phi_{\max } \\
\left(1-\phi_{\max }\right) \frac{\xi_{0}}{\phi_{\max }} \exp \left(-b \frac{T-T_{\mathrm{adi}}}{T_{\text {adi }}}\right), & \phi \geq \phi_{\max }\end{cases}
\end{gathered}
$$

We chose to introduce cut-offs for the porosity for two reasons. We need a minimum porosity $\phi_{\min }$ because the bulk viscosity is inversely proportional to the porosity, so that is has a singularity at $\phi=0$. Thanks to the numerical methods we employ (Dannberg et al., 2019), we can use a very small value of $\phi_{\min }$; in this study we choose a value of $2 \times 10^{-5}$. If the porosity is below that threshold, we no longer solve the coupled two-phase flow equations, but only the single phase Stokes equation for mantle convection (so the value of $\xi$ does not influence the solution any longer). Consequently, this lower cut-off is only a numerical threshold and does not influence the physical behaviour of the model.

In contrast, the upper threshold $\phi_{\max }$ does have implications for the modelled physics. Once the porosity of partially molten rocks reaches a given threshold, the disaggregation threshold, or rheolog- 
ically critical melt fraction (Kohlstedt \& Hansen, 2015), the rock ceases to form a connected matrix with pores that melt can flow through. Instead, the mixture of rock and magma forms a mush, and behaves as a melt containing suspended particles. Strictly speaking, the equations (1)-(4) we solve here only describe the flow of melt through the pores of a compacting host rock and are not applicable any longer once the rock matrix becomes disconnected. On the other hand, we are mostly interested in the processes that happen below the disaggregation threshold: Seismic observations suggest a melt fraction of the order of $10 \%$ in ULVZs, while the disaggregation threshold is at approximately $25-30 \%$ melt (Kohlstedt \& Hansen, 2015). In addition, our geodynamic models are not able to resolve the short time scales of flow within regions of mostly liquid melt. But as long as the viscosity in these areas is sufficiently small (several orders of magnitude smaller than within the solid rock, Kohlstedt \& Hansen (2015), figure 16), these high-porosity regions should not substantially affect the model evolution.

Accordingly, we add a lower limit to both the shear and bulk viscosity that corresponds to the values at the disaggregation threshold, which we take to be $\phi_{\max }=0.3$. With the melt weakening factor $\alpha_{\phi}=20$, the shear viscosity decreases by about a factor of 500 and the bulk yiscosity by a factor of 50 from $1 \%$ porosity to the disaggregation threshold. This effect is in addition to the decrease in viscosity caused by the high temperatures that facilitate such large melt fractions. The choice of the baseline value $\alpha_{\phi}=20$ is consistent with experiments investigating the influence of melt fraction on the shear viscosity in a diffusion creep regime for olivine-basalt and partially molten lherzolite lithologies under low pressures (Scott \& Kohlstedt, 2006; Kohlstedt \& Hansen, 2015). In this study, we vary this parameter to reflect uncertainties in the rheology of a partially molten lower mantle, and the potential influence of accelerated grain growth in regions of increased porosity, which would act to increase mantle viscosity.

For the reasons described above, our models do not accurately reproduce the physical behaviour of partially molten rocks with porosities aboye the disaggregation threshold, and so we do not interpret the internal structure of regions of high porosity, and show them as a uniform color in all of our figures.

\subsubsection{Other material properties}

For the permeability, we use the following constitutive law:

$$
k_{\phi}=k_{0} \phi^{3}(1-\phi)^{2}
$$

Usually, the permeability is assumed to depend on the porosity as $k \propto \phi^{n}$ with $2<n<3$. Physically, this behaviour is only reasonable as long as the melt fraction is below the disaggregation threshold. At $100 \%$ melt, the equations need to describe the single-phase flow of the melt. This means that as we approach $\phi=1$, it is a reasonable assumption that the relative velocities between the two phases 
should approach zero, and hence $k \rightarrow 0$. The permeability law we chose has been suggested for this purpose by Keller et al. (2013) (based on arguments made in Batchelor (1967); Abe (1995); HierMajumder et al. (2006)). Note that there are more generalized models for the permeability that bridge the regimes of two-phase porous and suspension flows by smoothly connecting the Darcy percolation coefficient for fluid flow through a porous matrix and the segregation coefficient for settling particles in the suspension limit (Keller \& Suckale, 2019). Since our model is not suited for resolving fluid flow above the disaggregation threshold, we decided to use this simpler model for the permeability given in (12).

We also have to choose a reasonable value for the reference permeability $k_{0}$. In the upper mantle, values on the order of $k_{0}=10^{-6}-10^{-9} \mathrm{~m}^{2}$ have been suggested. This also includes a presumed grain size dependence $k_{0} \propto d^{2}$ (Miller et al., 2014, and references therein). Because the grain size in the lower mantle may be much smaller than in the upper mantle, possibly by several order of magnitude (Dannberg et al., 2017; Yamazaki et al., 1996), we here vary the reference permeability between $5 \times 10^{-11}$ and $5 \times 10^{-13} \mathrm{~m}^{2}$.

In most of our models, we assume that the dihedral angle of silicate melt in the lowermost mantle is small enough for melt to form an interconnected network at small melt fractions, which is supported by experimental data (Panero et al., 2015). However, we also include models where melt is not allowed to move relative to the solid, corresponding to a permeability of 0 . This shows the first-order effects of surface tension, since strong surface tension (which results in a large dihedral angle between melt inclusions and solid mineral grains) would require large fractions of melt to form an interconnected network of pores that would allow melt to migrate. We do not explicitly include the effect of surface tension or interfacial energetics because (a) they are poorly constrained for lower mantle phases, and (b) we do not think that incorporation of these effects will significantly affect the model dynamics.

For simplicity, we assume the fluid viscosity and the thermal conductivity to be constant. All other material properties are computed using the equation of state (Appendix $\mathrm{C}$ ). The full set of model parameters is given in Table 1 .

\subsubsection{Model setup}

We model the lowermost $200 \mathrm{~km}$ of the mantle, and use a 2-D Cartesian model geometry with a horizontal extent of $600 \mathrm{~km}$ (see Figure 2). We use second-order finite elements and an adaptively refined mesh, with a maximum cell size of $6.25 \mathrm{~km}$ (in regions without melt) and a minimum cell size of $780 \mathrm{~m}$ (in regions with melt). The bottom and side boundaries of the model are closed, allowing for free flow parallel to the boundaries. These boundaries are also impermeable to chemical transport processes, as we assume that chemical interactions between mantle and core are negligible on the time 


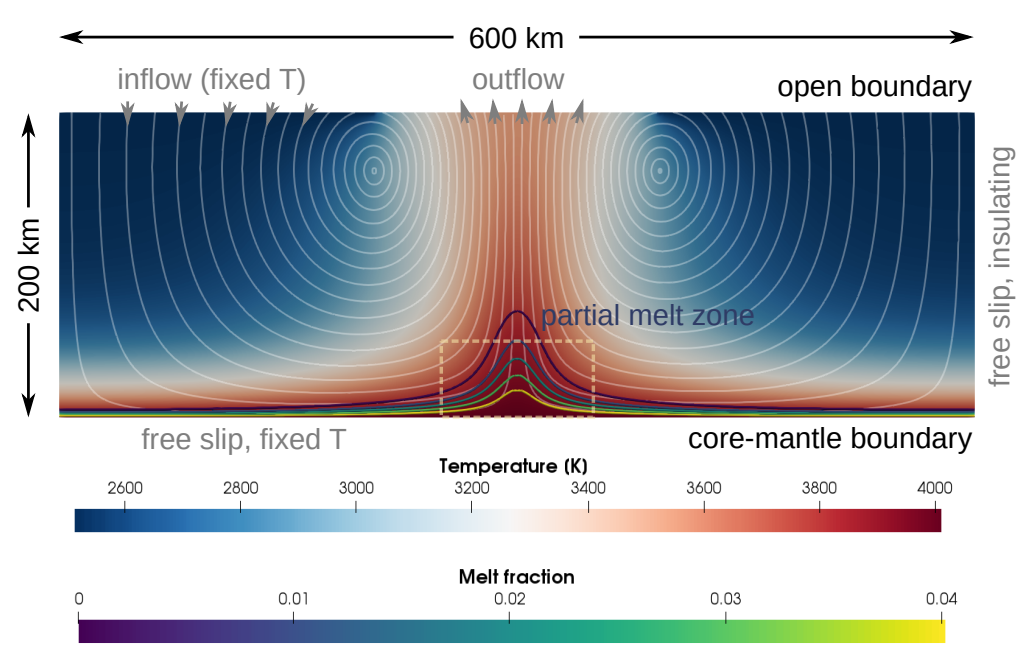

Figure 2. Model setup. Background colours illustrate the temperature, white streamlines illustrate the flow field, and yellow-to-blue contours illustrate melt fraction. The dashed outline indicates the part of the models shown in Figures 6, 8, 10 and 12.

scales of our model runs (for a more detailed discussion of this assumption, see Section 4.3). The top boundary is stress free in both vertical and horizontal direction and the pressure is normalized to be $125 \mathrm{GPa}$ on average along this boundary. This open boundary allows for free inflow and outflow of material.

We prescribe the temperature at the $\mathrm{CMB}$ to be equal to $4000 \mathrm{~K}$. We account for uncertainties in this value by varying the solidus temperature, as described later. At the top boundary, we only fix the temperature on the part of the boundary where material flows into the model, using a boundary temperature of $2512 \mathrm{~K}$. For our equation of state, this corresponds to a mantle adiabat with a potential temperature of $1600 \mathrm{~K}$ at the corresponding depth. The side walls are thermally insulating.

The model temperature stárts as an adiabatic profile, with an added thermal boundary layer at the bottom. We compute the thermal gradient within the conductive boundary layer using the half-space cooling model and an age of $50 \mathrm{Myr}$. We impose an additional small positive temperature perturbation at the bottom boundary of the model to guarantee that the plume that develops in the model is located in the center of the model domain.

We Ket all models evolve without any transport of melt (equivalent to setting the permeability to zero) for the first $150 \mathrm{Myr}$. This allows the models to reach a steady state where a plume has developed in the center of the model, and the amount and composition of melt present at its base is in equilibrium with this steady-state temperature and flow field. We then use this state as a starting point for models that solve the full equations including the migration of melt. 
Table 1. Parameters used in the geodynamic models.

\begin{tabular}{|c|c|c|c|}
\hline Property & Symbol & Value & Baseline \\
\hline Horizontal extent of the model $(\mathrm{km})$ & & 600 & \\
\hline Vertical extent of the model $(\mathrm{km})$ & & 200 & \\
\hline Mantle potential temperature $(\mathrm{K})$ & & 1600 & \\
\hline Core-mantle boundary temperature $(\mathrm{K})$ & $T_{\mathrm{CMB}}$ & 4000 & \\
\hline Solidus reduction $(\mathrm{K})$ & & 600,650 & 600 \\
\hline Reference shear viscosity (Pa s) & $\eta_{0}$ & $10^{23}$ & \\
\hline Reference bulk viscosity ( $\mathrm{Pa} \mathrm{s}$ ) & $\xi_{0}$ & $10^{23}$ & \\
\hline Exponential melt weakening factor & $\alpha_{\phi}$ & $-10 \ldots 27$ & 20 \\
\hline Thermal melt weakening factor & $b$ & 10 & \\
\hline Disaggregation threshold & $\phi_{\max }$ & 0.3 & \\
\hline Fluid (melt) viscosity (Pa s) & $\eta_{f}$ & 10 & \\
\hline Reference permeability $\left(\mathrm{m}^{2}\right)$ & $k_{0}$ & $5 \times 10^{-11}$ & \\
\hline Density contrast between melt and solid $\left(\mathrm{kg} / \mathrm{m}^{3}\right)$ & $\Delta \rho$ & $1000 \ldots-400$ & \\
\hline Thermal conductivity $(\mathrm{W} / \mathrm{m} / \mathrm{K})$ & $k$ & 8.5 & \\
\hline
\end{tabular}

\subsection{Thermodynamic model for lower mantle melting}

In the following sections, we will describe the thermodynamic model which we used to compute the melting behavior and the properties of the resulting solid and melt in our geodynamic simulations. We include a glossary with thermodynamic terminology in Table A1.

To introduce these sections, we start by listing the calculations that our thermodynamic model makes at every time step and at each point in the geodynamic simulation (see also right side of Figure 1):

(i) Query the geodynamic model for the pressure, temperature, solid composition, liquid composition and porosity. The coexisting liquid and solid may not be in chemical equilibrium with each other at this point, because of changes in pressure, temperature and relative flow of solid and melt computed during the previous time step.

(ii) Convert the porosity into mole fraction of melt using the molar volumes of the melt and solid (Appendix C), and use this to calculate the bulk composition.

(iii) Using the bulk composition, compute the molar melt fraction and the composition of melt and solid which are in equilibrium with each other (Section 2.2.1; Equations (14) and (15)). This calculation yields the reaction terms $\Gamma^{s}$ and $\Gamma^{f}$ (Equations (B.5) and (B.6)), 
(iv) Determine whether the system is now completely solid or liquid (Section 2.2.1),

(v) Calculate the latent heat of melting (Section 2.2.1),

(vi) Compute the composition of bridgmanite and ferropericlase and their molar proportions, based on the bulk solid composition (Section 2.2.2). Usually in thermodynamics, the solid phase compositions would be calculated at the same time as the melt composition. However, in order to use our simplified representation of the problem, these steps must be split into two,

(vii) Compute the properties, i.e. density, thermal expansivity, specific heat and compressibility, of the bulk solid (Section 2.2.2),

(viii) Compute the same properties for the bulk liquid (Section 2.2.2).

(ix) Convert the molar melt fraction to volume fraction (porosity), and from this calculate the melting rate $\Gamma$ (see Equation (B.4)).

(x) Pass the bulk properties and melting rate back to the geodynamic model.

Throughout this paper, we assume that the mantle is in local (i.e. finite-element-scale) thermodynamic equilibrium. This is a reasonable assumption, given that grain-scale chemical diffusion and reaction kinetics are likely to be much faster than the changes in pressure, temperature and composition which drive chemical reactions near the core-mantle boundary. This is especially true for regions undergoing partial melting, as melts (especially grain-boundary-wetting melts) facilitate chemical reactions, and have high chemical diffusivities. Empirically, these approximations can be justified by the fact that high pressure experiments on lower mantle assemblages approach equilibrium on a timescale of minutes to hours (e.g. Nakajima et al., 2012; Andrault et al., 2014).

We base the calculations in our study on the thermodynamic model of Boukaré et al. (2015). This model was developed in the $\mathrm{MgO}-\mathrm{FeO}-\mathrm{SiO}_{2}$ (FMS) chemical system, which encompasses about $90 \mathrm{wt} \%$ (also about 90 cation\%) of the bulk composition of typical ultramafic mantle rocks. We first briefly describe the model of Boukare et al. (2015), and then in the following sections we describe how we simplify that model in several ways to allow for more rapid evaluation of the properties required as inputs to the geodynamic model.

Solid phases considered by Boukaré et al. (2015) were (Mg, Fe)O ferropericlase; $(\mathrm{Mg}, \mathrm{Fe}) \mathrm{SiO}_{3}$ bridgmanite, and $\mathrm{SiO}_{2}$ (post-)stishovite. The melt phase was considered to be a subregular solution of $\mathrm{MgO}, \mathrm{FeO}$ and $\mathrm{SiO}_{2}$. Thermodynamic properties of the ferropericlase, bridgmanite and stishovite endmembers were taken from Stixrude \& Lithgow-Bertelloni (2011), $\mathrm{MgO}$ and $\mathrm{SiO}_{2}$ melt endmembers from de Koker et al. (2013) and the $\mathrm{FeO}$ melt endmember equation of state was developed by Boukaré et al. (2015). Melt interaction parameters for the $\mathrm{MgO}-\mathrm{SiO}_{2}$ system were approximated from de Koker et al. (2013), while the $\mathrm{MgO}-\mathrm{FeO}$ and $\mathrm{FeO}-\mathrm{SiO}_{2}$ melt binaries were assumed to be ideal. 


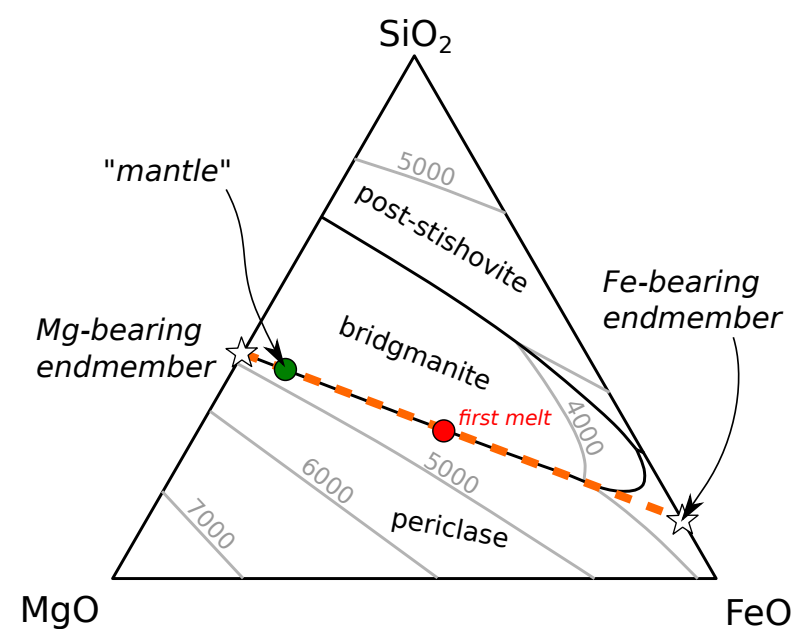

Figure 3. Calculated liquidus surface (in $\mathrm{K}$ ) in the $\mathrm{FeO}-\mathrm{MgO}-\mathrm{SiO}_{2}$ system at $130 \mathrm{GPa}$. Figure modified from Boukaré et al. (2015). The green dot represents a model mantle composition, and the red dot is the composition of the equilibrium melt at the mantle solidus. The orange dotted line shows the compositions corresponding to the pseudobinary system used in our model, with the endmember compositions plotted as stars.

For our paper, we implemented the Boukaré et al. (2015) model in the open-source software BurnMan (Cottaar et al., 2014). At $130 \mathrm{GPa}$, the model produces the liquidus surface shown in Figure 3.

\subsubsection{Binary melting parametrization}

Although the ternary system described by Boukaré et al. (2015) is already highly idealized, it cannot be reduced to a closed form expression giving melt and solid compositions as a function of temperature, pressure and bulk composition. Such expressions are desirable in geodynamic simulations, as they can be evaluated quickly. We therefore seek an alternative model which provides closed form expressions while still being able to approximate the melting behaviour seen in the Boukare et al. (2015) model.

The first useful observation is that a typical mantle composition lies close to the bridgmaniteferropericlase cotectic at $130 \mathrm{GPa}$ (Figure 3). Additionally, this cotectic is nearly linear in cation space. These two observations mean that both the melts and residues of mantle melting will lie approximately on the cotectic. We therefore decide to treat the mantle as a pseudobinary system, where both melt and solid always have bulk compositions which lie somewhere along the orange dotted line in Figure 3. The $\mathrm{MgO}-\mathrm{FeO}-\mathrm{SiO}_{2}$ concentrations for the Mg-bearing and Fe-bearing components bounding this pseudobinary system are defined in Table 2. In our geodynamic model, we now only need to track the molar proportion of the Fe-bearing component in the solid and melt to know the bulk composition at any point in the model (see Section 2.1.2). This simplification also allows us to use the closed-form expressions for the melting of a binary solution published by Phipps Morgan (2001) and described in the following section. 
Melt and solid composition We first consider a true binary system, in which an ideal solid solution composed of a mixture of an Mg-bearing endmember and an Fe-bearing endmember melts to form an ideal melt solution with endmembers of similar compositions. The melting of each solid endmember $i$ (where $i=\mathrm{Mg}$-mbr or Fe-mbr) is associated with changes in volume ( $\left.\Delta V_{\text {fus } i}\right)$ and entropy $\left(\Delta S_{\text {fus } i}\right)$, which are approximated to be pressure and temperature invariant. The Gibbs free energy change of fusion of endmember $i$ at a given pressure $P$ and temperature $T$ is then:

$$
\Delta \mathcal{G}_{\text {fus } i}=\left(T_{\text {fus }, \text { Pref }_{i}}-T\right) \Delta S_{\text {fus } i}+\left(P-P_{\text {ref } i}\right) \Delta V_{\text {fus } i}
$$

where $T_{\text {fus,Pref }}$ is the melting temperature of endmember $i$ at the reference pressure $P_{\text {ref } i}$.

If the solid and melt endmembers both mix ideally, then the compositions of coexisting liquid and solid can be calculated explicitly. Using the derivation in Phipps Morgan (2001), the fractions of the Fe-bearing endmember in the liquid and solid are given by:

$$
\begin{aligned}
& C_{f}=1-\left(\frac{1-c_{\mathrm{Fe}-\mathrm{mbr}}}{c_{\mathrm{Mg}-\mathrm{mbr}}-c_{\mathrm{Fe}-\mathrm{mbr}}}\right) \\
& C_{s}=C_{f} c_{\mathrm{Fe}-\mathrm{mbr}}
\end{aligned}
$$

with the nondimensional constants $c_{\mathrm{Mg}-\mathrm{mbr}}$ and $c_{\mathrm{Fe}-\mathrm{mbr}}$ given by

$$
\begin{aligned}
c_{\text {Mg-mbr }} & =\exp \left(\frac{\Delta \mathcal{G}_{\text {fus,Mg-mbr }}}{n_{\text {mix,Mg-mbr }} R T}\right) \\
c_{\text {Fe-mbr }} & =\exp \left(\frac{\Delta \mathcal{G}_{\text {fus,Fe-mbr }}}{n_{\text {mix,Fe-mbr }} R T}\right) .
\end{aligned}
$$

In these expressions, $n_{\text {mix }}$ represents the number of moles of cations involved in mixing per formula unit, and should strictly be the same for both endmembers.

The Fe-bearing endmember has the lower melting temperature. Therefore, if the bulk composition $C_{\text {bulk }}<C_{s}$, the solution is below the solidus and the solid composition and fraction should be set to $C_{\text {bulk }}$ and 1 respectively. If $C_{\text {bulk }}>C_{f}$, the solution is above the liquidus and the melt composition and fraction should be set to $C_{\text {bulk }}$ and 1 respectively. We use these expressions to compute the melting and compositional reaction rates $\Gamma, \Gamma^{s}$ and $\Gamma^{f}$ (Equations (B.4), (B.5) and (B.6)). These reaction rates are required to solve Équations (1), (2), (6) and (7) of the geodynamic model (see Section 2.1.2).

Neither the solid nor melt in our study are ideal binary solutions, nor are the compositions of the products and the reactants perfectly colinear. However, a good fit to the Boukare molar volumes, entropies and coexisting melt-solid compositions can be found if the two values of $n_{\text {mix }}$ are allowed to be independent (Table 2). We stress that the values given in Table 2 are purely empirical; they are not meant to represent the true melting process (which will be significantly more complex than the model presented by Boukaré et al. (2015)).

The pseudobinary melting loop and melt and solid densities are shown in Figure 4 and the corre- 
Table 2. Parametrization of the binary melt model. Model parameters are designed to fit the MgO-rich side of the bridgmanite-ferropericlase cotectic $(40<\mathrm{Mg \#}<100)$ from Boukaré et al. (2015). The last two rows give the parameter variations described in Section 2.3.1.

\begin{tabular}{|c|c|c|}
\hline Property & Mg-bearing endmember & Fe-bearing endmember \\
\hline Molar $\mathrm{MgO}$ concentration $\left(x_{\mathrm{MgO}}\right)$ & 0.581 & 0.000 \\
\hline Molar $\mathrm{FeO}$ concentration $\left(x_{\mathrm{FeO}}\right)$ & 0.000 & 0.908 \\
\hline Molar $\mathrm{SiO}_{2}$ concentration $\left(x_{\mathrm{SiO} 2}\right)$ & 0.419 & 0.092 \\
\hline Reference pressure $\left(P_{\text {ref }} ; \mathrm{Pa}\right)$ & $120 \mathrm{e} 9$ & $120 \mathrm{e} 9$ \\
\hline Melting temperature $\left(T_{\text {fus,Pref }} ; \mathrm{K}\right)$ & 4821.2 & 3424.5 \\
\hline Melting entropy ( $\left.\Delta S_{\text {fus }} ; \mathrm{J} / \mathrm{mol}\right)$ & 34.33 & 33.77 \\
\hline Melting volume ( $\Delta V_{\text {fus }} ; \mathrm{m}^{3} / \mathrm{mol}$ ) & $9.29 \cdot 10^{-8}$ & $1.51 \cdot 10$ \\
\hline$n_{\text {mix }}(\operatorname{mol})$ & 0.62 & \\
\hline Reference volume $\left(V_{0} ; \mathrm{m}^{3} / \mathrm{mol}\right)$ & $1.21804 \cdot 10^{-5}$ & $1.23255 \cdot 10^{-5}$ \\
\hline Adapted melting temperature $(\mathrm{K})$ & $4171.2 \ldots 4221.2$ & 2774. \\
\hline
\end{tabular}

sponding Fe-Mg partitioning coefficients in Figure 5. The solid:liquid Fe:Mg distribution coefficient $K_{\mathrm{Fe}-\mathrm{Mg}}^{\text {sol-liq }}\left(\left(\mathrm{Fe}_{\mathrm{sol}} / \mathrm{Fe}_{\text {liq }}\right) /\left(\mathrm{Mg}_{\mathrm{sol}} / \mathrm{Mg}_{\text {liq }}\right)\right)$ is about 0.135 for our model mantle composition, which equates to a factor of 7 enrichment of iron in the liquid relative to the solid. This is similar to the enrichment seen in the parent model (Boukaré et al. (2015); Figure 6, Points M and E). This enrichment is comparable to that reported from experiments on the olivine system (Nomura et al., 2011), but much greater than the factor $\sim 2$ enrichment observed in an Al-bearing system (Andrault et al., 2012). We will return to this point and its implications for melt density in Section 2.3.1.

Enthalpy of melting In order to include the effects of latent heat consumption and release upon melting and freezing in our geodynamic models (see Equation 5), we need to calculate the enthalpy changes during melting. For this purpose, we calculate the enthalpy of fusion of endmember $i$ :

$$
\Delta \mathcal{H}_{\text {fus } i}=T_{\text {fus, } \operatorname{Pref}_{i}} \Delta S_{\text {fus } i}+\left(P-P_{\text {ref }}\right) \Delta V_{\text {fus } i}
$$

where $S_{\text {fus } i}$ and $V_{\text {fus } i}$ are the fixed molar entropies and volumes of fusion of the Mg-bearing and Fe-bearing mantle endmembers (Table A2). Below the solidus, the enthalpy is equal to the solid enthalpy. Aboye the liquidus, the molar enthalpy of the liquid is equal to the solid enthalpy plus the enthalpy of fusion of the endmembers, weighted by the number of moles of each endmember in the bulk composition:

$$
\Delta \mathcal{H}=\left(1-C_{\text {bulk }}\right) \Delta \mathcal{H}_{\text {fus, Mg-mbr }}+C_{\text {bulk }} \Delta \mathcal{H}_{\text {fus,Fe-mbr }}
$$



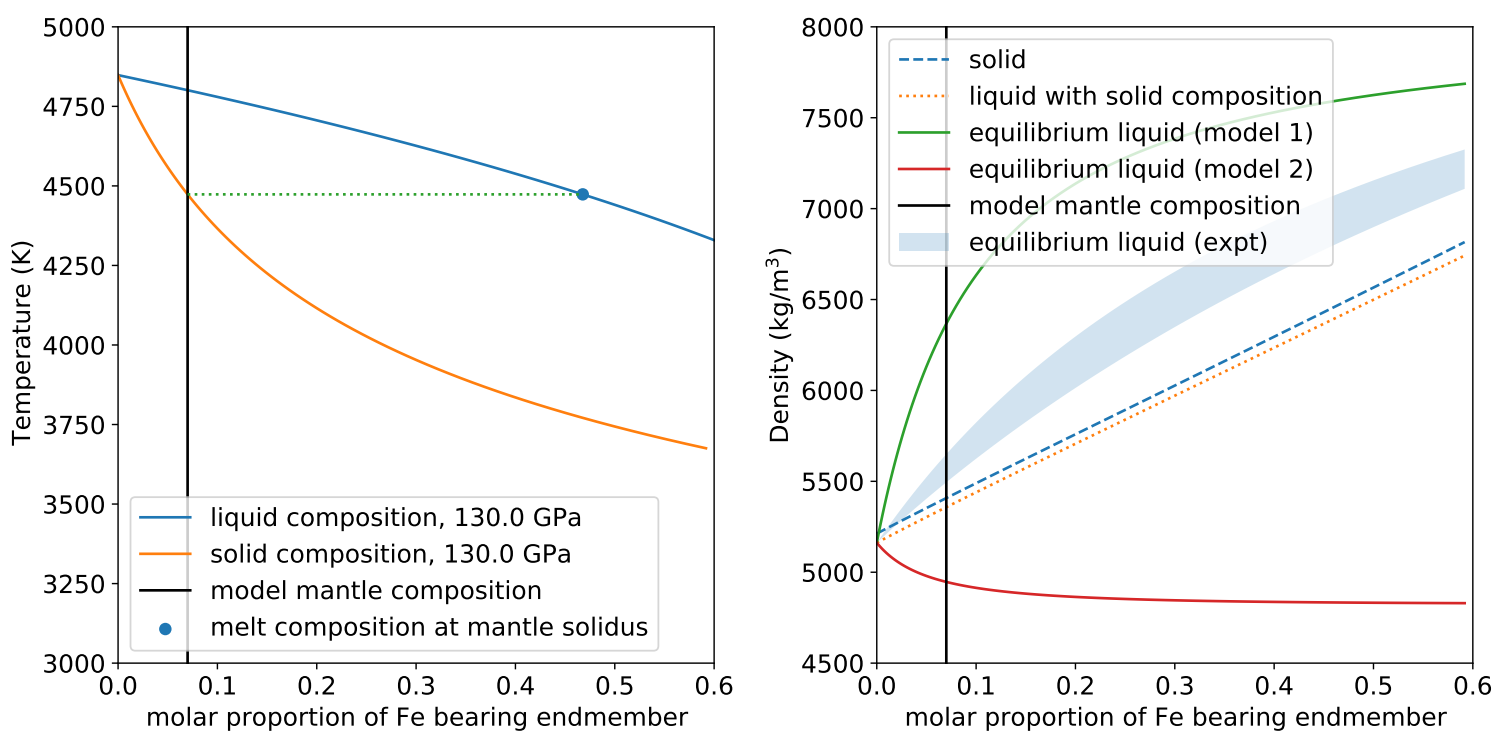

Figure 4. Melting model and density contrast between melt and solid for our pseudobinary melting system at $130 \mathrm{GPa}$ (orange line in Figure 3 for which the two endmember compositions are defined in Table 2). The starting composition for FMS pyrolite is 0.07 moles of the Fe-bearing endmember (vertical black line in both plots; equivalent to a composition of $\mathrm{Fe}_{0.06} \mathrm{Mg}_{0.54} \mathrm{Si}_{0.4} \mathrm{O}_{1.4}$ ). See equations (8) and (9) for how to convert to mole fractions of oxides. (Left) Solid and melt compositions in equilibrium with each other at a given temperature. (Right) Density of the solid and liquid at the onset of melting as a function of composition. The green line (model 1) refers to the baseline model densities which are similar to those predicted by the Boukare model, while the red line (model 2) refers to the model with minimum Fe-bearing melt densities. In our study we vary the Fe-bearing melt densities between these two bounds. The blue shaded area illustrates densities predicted using experimental partitioning data reported in the hiterature (Andrault et al., 2012). See Section 2.3 for a more detailed discussion.

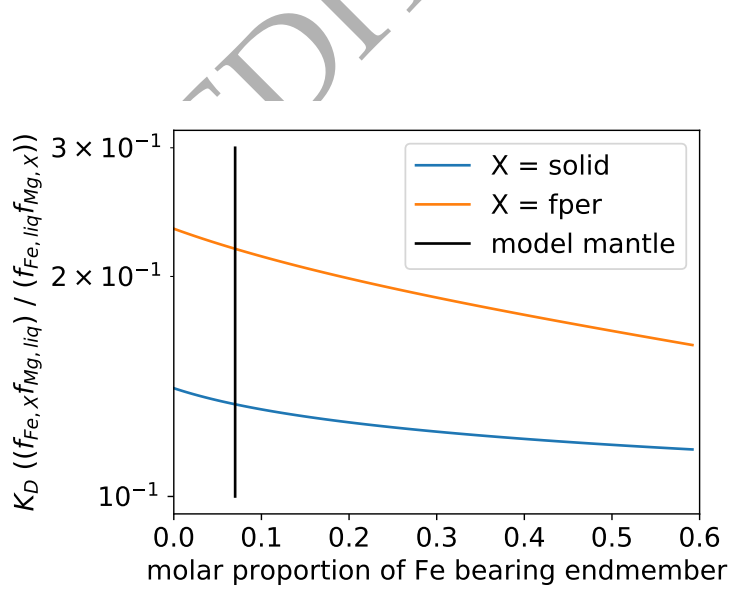

Figure 5. Model predictions for the Fe-Mg partition coefficient ( $\left.K_{\mathrm{Fe}-\mathrm{Mg}}^{\mathrm{sol}-\mathrm{liq}}\right)$ between solid and liquid (blue line) and ferropericlase and liquid (orange line) at the onset of melting at different bulk compositions at $130 \mathrm{GPa}$. Assumed mantle bulk composition is shown by the vertical black line. 
Between the solidus and the liquidus, the difference between the enthalpy of the solid-liquid mixture and the equivalent solid enthalpy at the same pressure, temperature and bulk composition is given by

$$
\begin{aligned}
\Delta \mathcal{H} & =f_{\text {liq }}\left(\left(1-C_{f}\right) \Delta \mathcal{H}_{\text {fus,Mg-mbr }}+C_{f} \Delta \mathcal{H}_{\text {fus,Fe-mbr }}\right) \\
f_{\text {liq }} & =\frac{C_{\text {bulk }}-C_{s}}{C_{f}-C_{s}}
\end{aligned}
$$

where $f_{\text {liq }}$ is the molar fraction of liquid.

\subsubsection{Thermodynamic properties}

Solid partitioning The pressure, temperature and bulk composition of the solid (expressed in molar proportion of the Fe-bearing endmember) are used to determine the properties of the solid. First, the molar proportions of $\mathrm{MgO}, \mathrm{FeO}$ and $\mathrm{SiO}_{2}$ in the solid are calculated from the compositions of the two endmembers (Table 2; Equations 8 and 9). The molar fraction of bridgmanite is then calculated from the proportion of $\mathrm{SiO}_{2}$ :

$$
f_{\text {bdg }}=\frac{x_{\mathrm{SiO}_{2}}}{\left(x_{\mathrm{MgO}}+x_{\mathrm{FeO}}\right)}
$$

where the parameters $x_{j}$ give the molar fraction of component $j$ in the solid. We assume ideal mixing of $\mathrm{Mg}$-Fe between ( $\mathrm{Mg}, \mathrm{Fe}) \mathrm{O}$ ferropericlase (per-wus) and ( $\mathrm{Mg}, \mathrm{Fe}) \mathrm{SiO}_{3}$ bridgmanite (mbdg-fbdg) (Nakajima et al., 2012), which yields a closed form expression for the partitioning of $\mathrm{Mg}$ and $\mathrm{Fe}$ between the two phases:

$$
\begin{aligned}
& p_{\mathrm{fbdg}}=\frac{-1+r-\left(r K_{\mathrm{D}}\right)+f_{\mathrm{bdg}}-\left(f_{\mathrm{bdg}} K_{\mathrm{D}}\right)+\sqrt{q}}{2 f_{\mathrm{bdg}}\left(1-K_{\mathrm{D}}\right)} \\
& p_{\mathrm{wus}}=\frac{p_{\mathrm{fbdg}}}{\left(1-p_{\mathrm{fbdg}}\right) K_{\mathrm{D}}+p_{\mathrm{fbdg}}}
\end{aligned}
$$

The parameters $p_{\mathrm{i}}$ correspond to the molar proportions of endmember $i$ in their respective solid solution, with

$$
\begin{aligned}
K_{\mathrm{D}} & =\exp \left(\frac{\mathcal{G}_{\mathrm{rxn}}}{R T}\right) \\
\mathcal{G}_{\mathrm{rxn}}(P, T) & =\mathcal{G}_{\text {mbdg }}+\mathcal{G}_{\mathrm{wus}}-\mathcal{G}_{\mathrm{fbdg}}-\mathcal{G}_{\mathrm{per}} \\
q & =\frac{x_{\mathrm{FeO}}}{\left(x_{\mathrm{MgO}}+x_{\mathrm{FeO}}\right)} \\
& =-4 r\left(K_{\mathrm{D}}-1\right) K_{\mathrm{D}} f_{\mathrm{bdg}}+\left(1+\left(r\left(K_{\mathrm{D}}-1\right)\right)+\left(\left(K_{\mathrm{D}}-1\right) f_{\mathrm{bdg}}\right)\right)^{2}
\end{aligned}
$$

where $K_{\mathrm{D}}=K_{\mathrm{Fe}-\mathrm{Mg}}^{\mathrm{bdg}}$ is the ratio of ratios between Fe:Mg and bridgmanite:ferropericlase, i.e.:

$$
K_{\mathrm{D}}=\frac{p_{\text {fbdg }} / p_{\text {mbdg }}}{p_{\text {wus }} / p_{\text {per }}}
$$


In these expressions, $R$ is the gas constant and $T$ is the temperature. $\mathcal{G}_{\mathrm{rxn}}(P, T)$ is the Gibbs free energy of the reaction fbdg + per $\rightarrow$ mbdg + wus, which can be calculated using the equations of state for the endmembers.

Endmember and solution properties Equations of state for Mg-bridgmanite, Fe-bridgmanite, periclase, wüstite, and the Mg-bearing and Fe-bearing melt endmembers are provided in Appendix C. The equation of state defines the molar Gibbs free energy $\mathcal{G}$ for each endmember. The Gibbs free energies of the solid endmembers of bridgmanite (mbdg, fmdg) and ferropericlase (per, wus) are calculated using a $P-T$ explicit equation of state based on Holland \& Powell (2011). The parameters for the equation of state are fit by least squares minimization such that the equations of state closely approximate those used by Boukaré et al. (2015) (Table A2). Maxwell's relations and partial derivatives of the molar Gibbs free energy with respect to pressure and temperature yield the densities, isothermal compressibilities, molar heat capacities and thermal expansivities of each endmember, which are required inputs for Equations (1)-(5) of the geodynamic model (see Section 2.1.1).

We calculated bulk properties of the solid and melt by consistent averaging of endmember properties. Molar properties (molar volume, molar heat capacity, molar mass) are arithmetically averaged with molar fractions. Density can then be calculated by dividing the molar mass by molar volume. The isothermal compressibilities, and thermal expansivities are arithmetically averaged by volume fraction.

The eagle-eyed reader will have noticed that by defining the bulk properties of the solid and melt through endmember equations of state, we break self-consistency with the melt model defined in Section 2.2.1 (Table 2). However, the equation of state parameters given in Appendix C yield volumes and entropies of melting which are very close to that model, so there is no significant impact on the model results. A major benefit of decoupling the melting model from the calculation of material properties is that we are able to change the effective partial molar volumes of the melt endmembers to approximate the effect of unmodelled chemical components such as $\mathrm{Al}_{2} \mathrm{O}_{3}$ on the geodynamics (see Section 2.3).

\subsection{Modification of the baseline melting model}

\subsection{Variation of melt model parameters}

There are significant uncertainties associated with many aspects of melting in the lowermost mantle. In adapting the model presented by Boukaré et al. (2015), we have so far ignored these uncertainties, and have additionally made several approximations (Section 2.2.1). However, because we want to 
investigate the range of plausible mantle behaviour, we will also present simulations where the baseline model parameters are modified.

Key uncertainties in the pyrolite system include:

- the melting temperatures at the bridgmanite-ferropericlase eutectic in the $\mathrm{MgO}-\mathrm{SiO}_{2}$ system (de Koker et al., 2013; Baron et al., 2017),

- depression of melting temperature with the addition of further components (especially $\mathrm{FeO}$, $\mathrm{Al}_{2} \mathrm{O}_{3}$ and $\left.\mathrm{CaO}\right)$,

- the volume (density) and entropy of melting,

- partitioning of iron and other elements (especially the major elements $\mathrm{Al}_{2} \mathrm{O}_{3}$ and $\mathrm{CaO}$ ) between the solid and melt.

We choose to vary two sets of parameters. First, we vary the melting temperatures for both endmembers of the bridgmanite-ferropericlase cotectic (see Table 2). We note that the melting model described in Section 2.2.1 predicts a solidus temperature which is $500 \mathrm{~K}$ hotter than our best guess of the present-day CMB temperature of around $4000 \mathrm{~K}$ (e.g. Boehler, 2000; Hernlund et al., 2005; Lay et al., 2008; Anzellini et al., 2013). Taken at face value, this would rule out a simple mantle melting origin for ULVZs. In this study, we therefore focus on scenarios where the solidus of the mantle is several hundred kelvin lower than predicted by the model taken from Boukaré et al. (2015). This might arise because experiments currently overestimate melting temperatures in the $\mathrm{MgO}-\mathrm{FeO}-\mathrm{SiO}_{2}$ system, or because of a depression in solidus temperatures due to other unmodelled, chemical components. Alternatively, the true CMB temperature might lie at the upper end of geophysical estimates.

Secondly, we vary the volume of fusion of the iron-bearing endmember in the melt (see Table 2). While there are uncertainties in the partial volume of fusion of $\mathrm{FeO}$ in silicate melts in the lowermost mantle, we vary this parameter mainly to investigate the addition of other components to the system which would reduce the enrichment of FeO (the densest component) in the melt. A particularly important component in this respect is alumina. Experiments on aluminous bridgmanite-ferropericlase assemblages suggest that the incorporation of alumina into bridgmanite is charge-coupled with ferric iron (Frost \& Langenhorst, 2002; McCammon et al., 2004). As a result, the total iron concentration in bridgmanite increases with alumina content, even if the $\mathrm{Fe}^{2+}-\mathrm{Mg}$ partition coefficient with ferropericlase remains the same (Nakajima et al., 2012; Frost \& Myhill, 2015). This means that melts in aluminous bulk compositions will tend to have lower concentrations of iron, because more of the iron is partitioned into bridgmanite. There remains uncertainty over the extent of the reduction in iron enrichment, and the influence of other elements on iron partitioning. Simple thermodynamic arguments based on observed bridgmanite-ferropericlase partitioning (Nakajima et al., 2012; Frost \& Myhill, 2015) and Al-free solid-melt partitioning (Irifune et al., 2010) suggest that the apparent 
$K_{\mathrm{Fe}-\mathrm{Mg}}^{\text {sol-liq }}$ (including both $\mathrm{Fe}^{2+}$ and $\mathrm{Fe}^{3+}$ in the total) should increase from 0.135 to 0.17 (see Appendix $\mathrm{D}$ for an example calculation). This corresponds to an atomic iron distribution coefficient $\left(D=(\mathrm{Fe} /(\mathrm{Mg}+\mathrm{Fe}+\mathrm{Si}))_{\mathrm{sol}} /(\mathrm{Fe} /(\mathrm{Mg}+\mathrm{Fe}+\mathrm{Si}))_{\text {liq }}\right.$ of $D=0.23$. In contrast, high pressure diamond anvil experiments suggest a much larger coefficient of $D=0.47 \pm 0.09$ at $120 \mathrm{GPa}$ (Andrault et al., 2012) $\left(K_{\mathrm{Fe}-\mathrm{Mg}}^{\mathrm{sol}-\mathrm{liq}} \sim 0.43 \pm 0.09\right)$.

Projected onto the Fe-Mg-Si ternary diagram, the new melt compositions still lie close to the cotectic line in Figure 3. The binary melt model can therefore still be used to estimate the experimental melt densities. These are shown as the blue shaded region in Figure 4. The corresponding solid densities at the solidus are only changed on the order of $10 \mathrm{~kg} / \mathrm{m}^{3}$ by the addition of alumina. Therefore, melting at the solidus is predicted to create melts with excess densities of $150 \pm 70 \mathrm{~kg} / \mathrm{m}^{3}$. These estimated densities are still somewhat higher than neutral buoyancy or even a slightly positive buroyancy, as proposed by Andrault et al. (2012) on the basis of measurements on the density of glasses at room temperature (Funamori \& Sato, 2010).

Considering the uncertainties in melt compositions and corresponding densities predicted by thermodynamics, high temperature experiments and the compression of glassy melt analogues, it would be premature to construct a complete thermodynamic melt model incorporating alumina and other chemical components. Instead, we approximate the effect of these components on melt densities by keeping the binary melting model the same and varying the density of the iron-bearing melt endmember (see Table 2). The changes of melt fraction with bulk iron content, pressure and temperature are therefore unchanged, but the density of the corresponding melt is allowed to vary within the range described above.

\subsection{Computing seismic velocities}

To compare the output from our ASPECT/models to seismological observations of ULVZs, we estimate seismic velocity variations in the models as a function of temperature, melt content, and respective compositions of the melt and solid using BurnMan (Cottaar et al., 2014). For the solid silicates, we use the database of Stixrude \& Lithgow-Bertelloni (2011) and the equation-of-state formulations in Stixrude \& Lithgow-Bertelloni (2005). For the bulk sound velocities of the melt, we apply the properties from Boukaré et al. (2015) and the modified equation-of-state from Holland \& Powell (2011) (see Section 2.2.2). We adapt the melt density to be consistent with the geodynamic computation by changing the molar volume of the Fe-endmember in the melt. The velocity reductions largely depend on how the solid and melt elastic parameters are averaged, which is subject to the unknown geometry of the pore spaces in which the melt sits (e.g. Takei, 2002; Wimert \& Hier-Majumder, 2012; Takei, 2017; Rudge, 2018). We assume an equilibrium geometry with a dihedral angle of $20^{\circ}$ and linearize 
the effect on averaged shear and bulk modulus, $\mu_{\text {eff }}$ and $K_{\text {eff }}$, as a function of melt fraction $\phi$, and the moduli for the solid $K_{s}$ and $\mu_{s}$ and fluid $K_{f}$ (using equation 3 and Figure 2 in Takei (2002)):

$$
\begin{gathered}
\mu_{\text {eff }}=\left(1-\frac{0.28}{0.063} \phi\right) \mu_{s} \\
K_{\text {eff }}=K_{b}+\frac{K_{s}\left(1-K_{b} / K_{s}\right)^{2}}{1-\phi-K_{b} / K_{s}+\phi K_{s} / K_{f}}
\end{gathered}
$$

where

$$
K_{b}=\left(1-\frac{0.4}{0.06} \phi\right) K_{s}
$$

We assume this formulation is only valid to estimate average velocities at low melt fractions before disaggregation of the solid matrix occurs, and note that the shear wave velocity becomes zero at $22.5 \%$ melt.

The resulting velocities are then computed by $V_{S}=\sqrt{\mu_{\text {eff }} / \rho}$ and $V_{P}=\sqrt{\left.\left(K_{\text {eff }}\right)+4 / 3 \mu_{\text {eff }}\right) / \rho}$, where $\rho$ is the averaged density. To give a rough idea of the various controls on velocity in our model, the shear wave velocity is reduced by $\sim 2.5 \%$ for a $1000 \mathrm{~K}$ increase in temperature, a $7.5 \%$ increase in iron content, or by including $1 \%$ of melt.

\section{RESULTS}

\subsection{Geodynamic Results}

\subsubsection{Model evolution}

We first describe the evolution of a representative model (using the parameters given in the column labelled "baseline" in Table 1), and then discuss how the different parameters influence the model evolution. As pointed out in Section 2.1.5, we start all of our models from a steady state without melt transport as shown in the top panel of Figure 6. The steady state features a plume stem in the center of the model, hot material leaving the model domain at the top, and a dome-shaped region of partial melt at the base of the plume, where temperatures are highest. Due to the temperature distribution, the amount of melt is largest near the CMB $(\sim 6.5 \%)$ and decreases further upwards in the plume. The melt fraction falls below $1 \%$ approximately $50 \mathrm{~km}$ above the CMB in the plume center.

In the representative model, melt starts to sink towards the CMB as soon as it is allowed to move relative to the solid. This behaviour is caused by the higher density of the melt, and generates solitary waves, a characteristic feature of the melt migration equations (e.g. Barcilon \& Richter, 1986; Barcilon \& Lovera, 1989; Spiegelman, 1993). Melt sinks downwards fastest in the parts of the model where 
the permeability is large, which are the regions with the highest amount of melt being present right above the CMB. Since the melt is enriched in iron compared to the residual, this downwards melt migration leads to a change in composition: A thin layer of partial melt forms just above the CMB, which becomes enriched in iron, and the upstream melt source region becomes depleted in iron. The iron-depleted source region of the melt has a low density, and is transported upwards into the mantle plume, allowing new material from the surrounding mantle to enter the melting zone. The increase in iron content in the bottom layer leads to a decreasing melting temperature, and the equilibrium melt fraction of this iron-rich layer increases even though the temperature does not change substantially. This means that more melt can accumulate in this bottom layer without crystallizing. Consequently, the melt fraction in this layer increases over time, reaching 30\% (disaggregation) after only 7 Myr. Due to the high melt density, this melt layer is too dense to be entrained in the rising mantle plume, and grows over time as new material enters the base of the plume stem and melts. After 100 Myr of melt migration, the melt layer is approximately $5 \mathrm{~km}$ thick (in the center) and contains on average about $48 \%$ melt, with the melt fraction increasing from top to bottom. Since there is no process that prevents the melt layer from growing, this model does not reach a steady state. An animation of the model evolution in terms of temperature, melt fraction, and composition can be found in Supplementary Video 1, and the velocity field is visualized in Figure A2.

This type of model evolution is neither consistent with the observed velocity reductions in ULVZs, nor the thermal and chemical evolution of the Earth in general. As soon as the solid rock matrix stops being connected and the partially molten layer mechanically behaves like a liquid, it would not appear as the reduction in S-wave velocity that is obseryed for ULVZs. Instead it would look like outer core topography with a sharp reflection of S-waves, and an anomalous P-wave velocity (of molten iron-rich silicate instead of molten iron, see also Section 3.2). Moreover, since the Earth is cooling, we would not expect a magma ocean to grow at the base of the mantle today, and if such a melt layer was present at the base of the mantle, it would be visible through seismic observations. While the representative model does not seem to match Earth's present-day state, a number of parameters can significantly modify the model behavior. In order to understand if a realistic model result can be achieved with reasonable parameter variations we analyze and test the influence of these parameters in the next sections.

\subsubsection{Parameters controlling the model}

To determine which of the model parameters are most important for model evolution, we will start from the analysis of Hernlund \& Jellinek (2010). They identify two key non-dimensional parameters, 

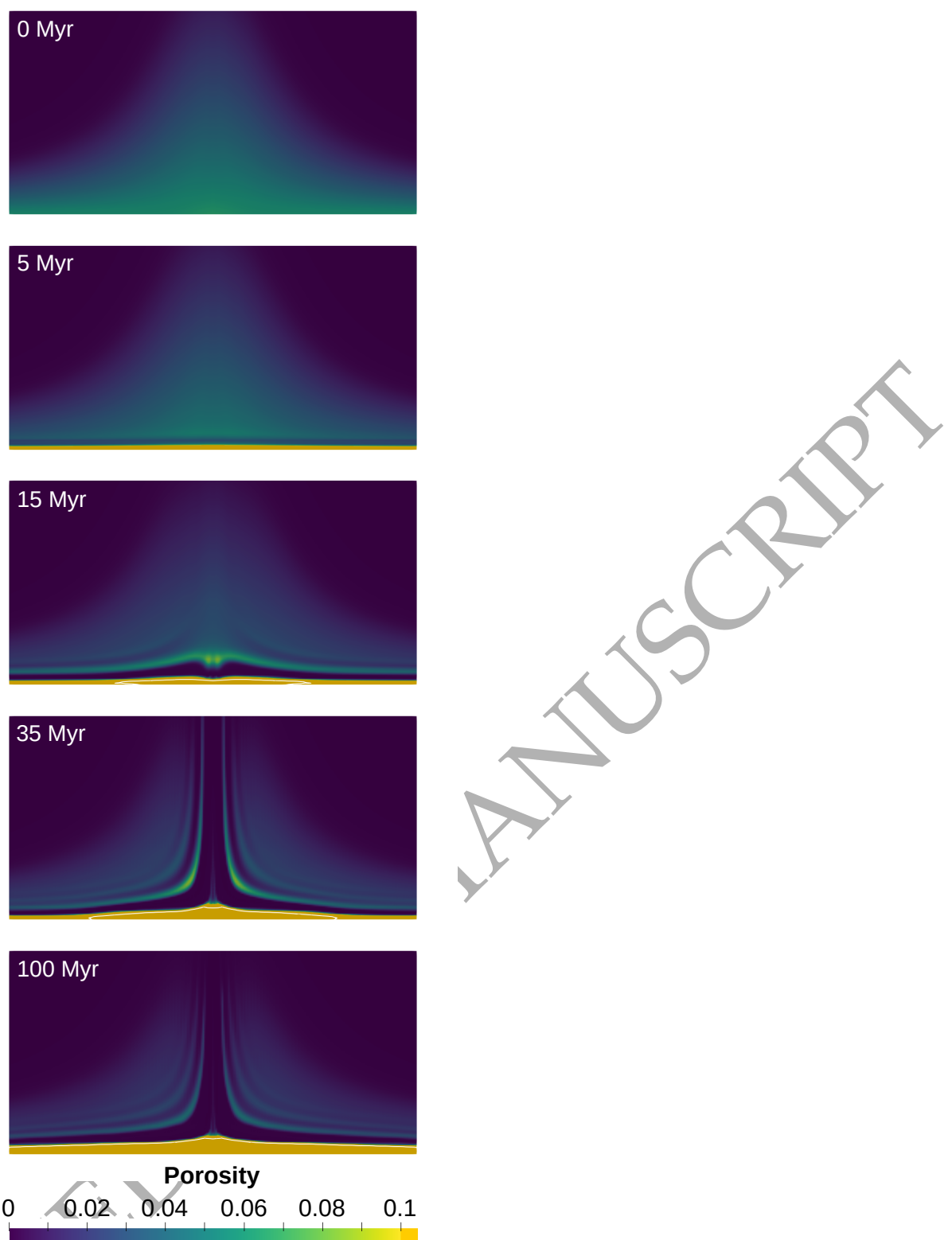

Figure 6. Evolution of the partial melt zone in the baseline model. The white contour indicates a porosity of $30 \%$ (disaggregation). All panels show a $100 \mathrm{~km} \times 50 \mathrm{~km}$ clip of the model centered around the partial melt zone, with the time after the start of melt migration indicated in each panel.

$R$ and $\delta$, in the governing equations:

$$
\begin{aligned}
R & =\frac{\Delta \rho g H^{2}}{\eta_{s} v_{0}}, \\
\delta^{2} & =\frac{\eta_{s} k_{0}}{\eta_{f} H^{2}}
\end{aligned}
$$

$R$ is a ratio of two time scales: the time scale for buoyant diapiric rise of a molten body through a viscous solid matrix, and the time scale for imposed stirring of the ULVZ by the surrounding mantle 


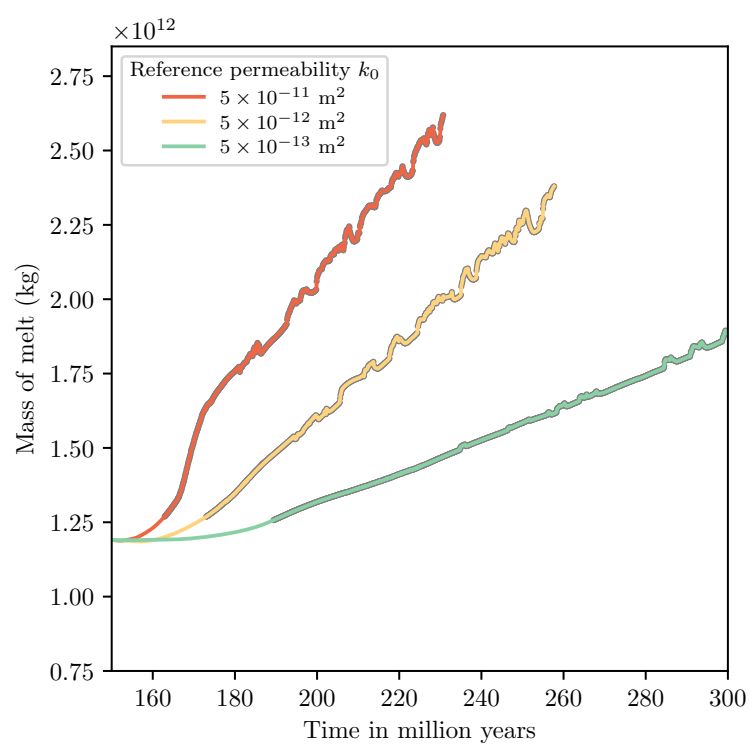

Figure 7. Evolution of the amount of melt in models with different permeabilities over time. The gray outline starts when the melt fraction reaches $80 \%$ in a given model. In all models the melt layer grows over time, and it grows faster with increasing permeability.

flow. The time scale for buoyant diapiric rise $\eta_{s} / \Delta \rho g H$ is controlled by the viscosity $\eta_{s}$ within the partial melt zone, the buoyancy of the melt imposed by its density contrast $\Delta \rho$, and the characteristic length scale of the partial melt zone $H$. The time scale of stirring of the ULVZ $H / v_{0}$ is controlled by the ULVZ circulation velocity $v_{0}$ induced by the mantle flow. Since we do not impose the stirring velocity, but let convection evolve freely, driven by the temperature contrast at the CMB, the stirring velocity develops based on the Rayleigh number and the length scale of the model. Accordingly, it is influenced by the viscosity outside of the partial melt zone.

$\delta$ is the non-dimensional effective compaction length, which is normalized by the characteristic length scale of the partial melt zone $H$. It has been described as a characteristic length scale for magma dynamics, and depends on the melt fraction, the melt viscosity and the permeability (Hernlund \& Jellinek, 2010).

Within our formulation of thermodynamic properties and melting model (see Sections 2.2.2 and 2.2.1), we can vary $\delta$ and $R$ by varying the reference permeability $k_{0}$ and the melt weakening factor $\alpha_{\phi}$, respectively. The permeability controls not only the characteristic length scale, but also how fast melt percolation occurs. $\alpha_{\phi}$ controls how much weaker the partial melt zone is compared to the surrounding mantle, so that a larger $\alpha_{\phi}$ decreases the time scale for buoyant diapiric rise while leaving the time scale of stirring unchanged. Conversely, changing the background viscosity $\eta_{0}$ would affect both time scales equally and leave $R$ unchanged.

Figure 7 shows how the amount of melt in the partial melt zone in our model evolves over time. 


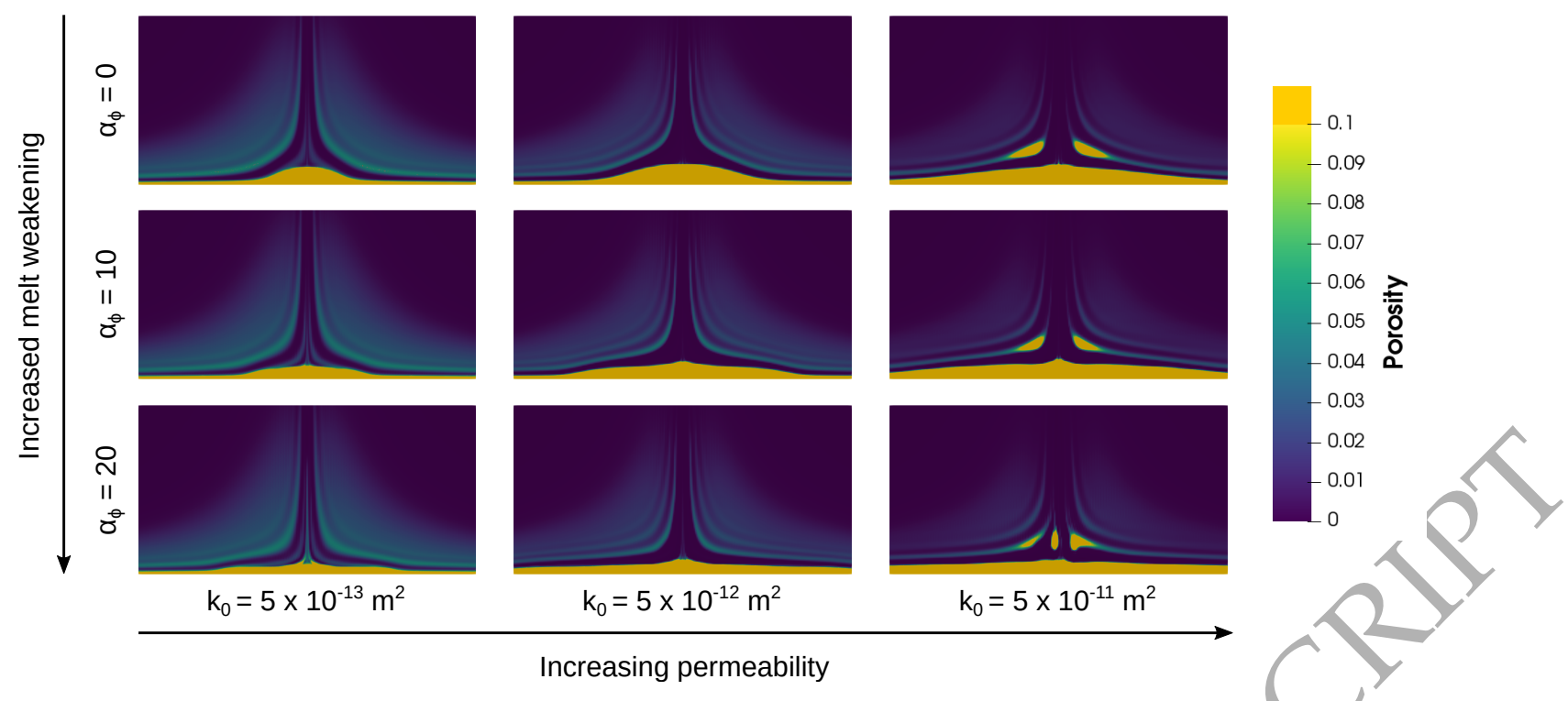

Figure 8. Morphology of partial melt zones in models with different permeabilities (left-to-right) and melt weakening (top to bottom). All panels show a $100 \mathrm{~km} \times 50 \mathrm{~km}$ clip of the model centered around the partial melt zone, 80 Myr after the start of melt migration.

In all models, a substantial fraction of the melt that is generated sinks to the CMB and accumulates in a melt-rich layer (like in the baseline model shown in Figure 6). Consequently, all models show an increase in the amount of melt over time, and none of the models reaches a steady state. The permeability influences the time scale of this melt accumulation: The larger the permeability, the faster melt can sink, and the faster it accumulates. For lower permeabilities, more melt reaches the central part of the plume where material is ascending and is entrained before it can sink down to the melt-rich layer. The viscosity of the partial melt zone does not influence how fast melt accumulates, but instead controls the shape of this melt-rich layer at the CMB. Larger values of $\alpha_{\phi}$, corresponding to a weak partial melt zone, lead to flat and thin melt-rich layers. The stronger the partial melt zone, the larger the topography, and the smaller the aspect ratio of the melt-rich layer.

However, all of the models feature a constantly growing melt-rich layer, which means they are not consistent with the hypothesis of ULVZs as zones of partial melt approximately in steady-state with the surrounding flow (as outlined in Section 3.1.1).

We can also relate this model evolution to the models and analysis of Hernlund \& Jellinek (2010). They found that for values of $R>1$, gravity-driven separation of melt and solid dominates and melt accumulates in a melt-rich layer at the base of the model. For $R<1$, melt can be retained within the matrix of the solid host rock, staying in suspension. In our models, $H \approx 20 \mathrm{~km}, v_{0} \approx 3-5 \mathrm{~cm} / \mathrm{yr}$, $\eta_{\mathrm{ULVZ}} \approx 2 \cdot 10^{20} \mathrm{~Pa} \mathrm{~s}$ (without considering melt weakening), $g=10 \mathrm{~m} / \mathrm{s}^{2}$ and $\Delta \rho \approx 1000 \mathrm{~kg} / \mathrm{m}^{3}$. This 
results in $R=15 \gg 1$. $R$ is more than an order of magnitude too large for melt to stay in suspension, which explains why accumulation of melt at the CMB is a common feature of all the models.

Note that this is a very different value for $R$ compared to the prediction of Hernlund \& Jellinek (2010). They assume the density difference between the solid and liquid phases $\Delta \rho$ to be in the order of $1 \%$ (or $50 \mathrm{~kg} / \mathrm{m}^{3}$ ), and their models do not include thermal effects, so they assume the same viscosity of the solid inside and outside the partial melt zone. Consequently, they predict much smaller values of $R \ll 1$.

The density contrast between melt and solid in our simulations is a direct consequence of our model parametrization (Figure 4). Densities of the bridgmanite and ferropericlase solid solutions are well-constrained experimentally (Stixrude \& Lithgow-Bertelloni, 2011; Holland et al., 2013b). Endmember liquid densities are less well-known, but high pressure experiments provide constraints on melt structure (Funamori, 2004; Funamori \& Sato, 2010; Kono et al., 2018) and melting curves (Komabayashi, 2014; Zhang \& Fei, 2008; Kimura et al., 2017; Baron et al., 2017; Millot et al., 2015), which are supported by ab initio molecular dynamics (de Koker et al., 2013). These suggest that MgO, $\mathrm{FeO}$ and $\mathrm{SiO}_{2}$ liquids remain slightly less dense than their solid counterparts at the base of the mantle, and that excess volumes of mixing tend to decrease in absolute magnitude with increasing pressure. The large negative buoyancy in our simulations is therefore not caused by a density difference between melt and solid of identical chemical compositions, but instead a consequence of strong partitioning of dense ferrous iron into the melt (see also Figure 4). While this partitioning behaviour is supported by experiments in the $\mathrm{MgO}-\mathrm{FeO}-\mathrm{SiO}_{2}$ system (Nomura et al. 2011), other experiments suggest that the addition of other components (especially $\mathrm{Al}_{2} \mathrm{O}_{3}$, see also Section 2.3.1) may reduce the strength of this partitioning (Andrault et al., 2012). We investigate this further in the next section.

\subsubsection{Influence of the melt density}

Above, we have shown that using our baseline melting model, partial melt derived from pyrolitic bulk compositions does not remain suspended in the solid mantle, but instead accumulates in a melt-rich layer at the base of the mantle, which is not consistent with observations of ULVZs.

We now consider simulations where we artificially increase the reference molar volume of the iron-bearing melt endmember, which decreases the density difference between melt and solid $\Delta \rho$. The parameter values are given in Table 2 , and they lead to variations in the density difference between melt and solid between our original value of $\Delta \rho \approx 1000 \mathrm{~kg} / \mathrm{m}^{3}$ and $\Delta \rho \approx-400 \mathrm{~kg} / \mathrm{m}^{3}$ (corresponding to a melt that is less dense than the solid). These density differences given here and later throughout the manuscript apply to the very first melt that forms at the solidus at CMB conditions, which contains the most iron. For larger melt fractions, this density difference is smaller because the chemical com- 


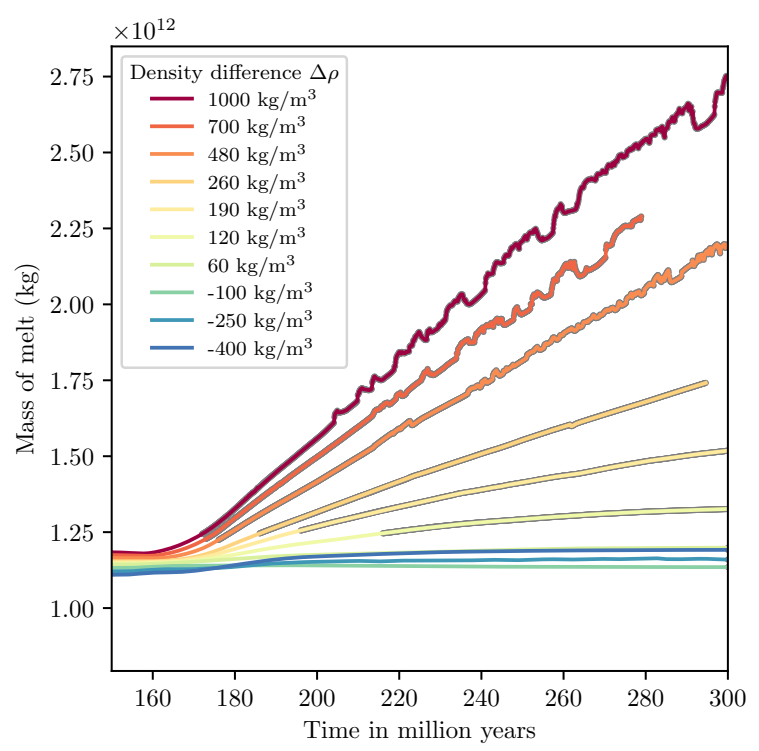

Figure 9. Evolution of the amount of melt in models with different melt densities over time. The gray outline indicates when the melt fractions reach $80 \%$ in a given model. All models below $R=1$ (which corresponds to $\Delta \rho=64 \mathrm{~kg} / \mathrm{m}^{3}$ ) remain at a lower maximum melt fraction and reach a steady-state.

position of the melt is closer to the source material (see also Figure 4). This variation reflects both the uncertainty of the experiments and/or the uncertainty in composition (see Section 2.3.1).

Reducing the density of the melt decreases the ratio $R$ we have used to analyze the model behaviour in Section 3.1.2, shifting the force balance towards the dominance of melt segregation driven by matrix stress (Hernlund \& Jellinek, 2010). Accordingly, we see a shift in model behaviour (Figure 9): For large melt densities, melt continues to accumulate in a melt-rich layer at the base of the mantle, illustrated by the continuous increase of the amount of melt in the model over time. For lower melt densities (small or even negative density difference compared to the solid), more melt stays suspended in the mantle flow, is entrained into the rising plume, and eventually freezes again when it reaches colder parts of the mantle. The models eventually reach a steady-state, where the amount of new melt being generated is balanced by the amount of melt that freezes. These models are more consistent with current observations of ULVZs, since only low fractions of partial melt are present in the steady state, and there is no melt layer growing at the base of the mantle. The flip between the two regimes occurs at a density difference of $\Delta \rho \approx 60 \ldots 120 \mathrm{~kg} / \mathrm{m}^{3}$, corresponding to $R$ between 1 and 2 .

The change in melt density also significantly modifies the morphology of the partial melt zone (Figure 10, densities shown in Figure A3). For melt that is only slightly denser than the solid (Figure $10, \Delta \rho=120 \mathrm{~kg} / \mathrm{m}^{3}, \Delta \rho=60 \mathrm{~kg} / \mathrm{m}^{3}$ ), some of the melt stays suspended and does not move very far from its source region before it is entrained in the plume. Conversely, the melt that sinks down to the base of the mantle is swept towards the base of the plume conduit by the converging mantle flow, 

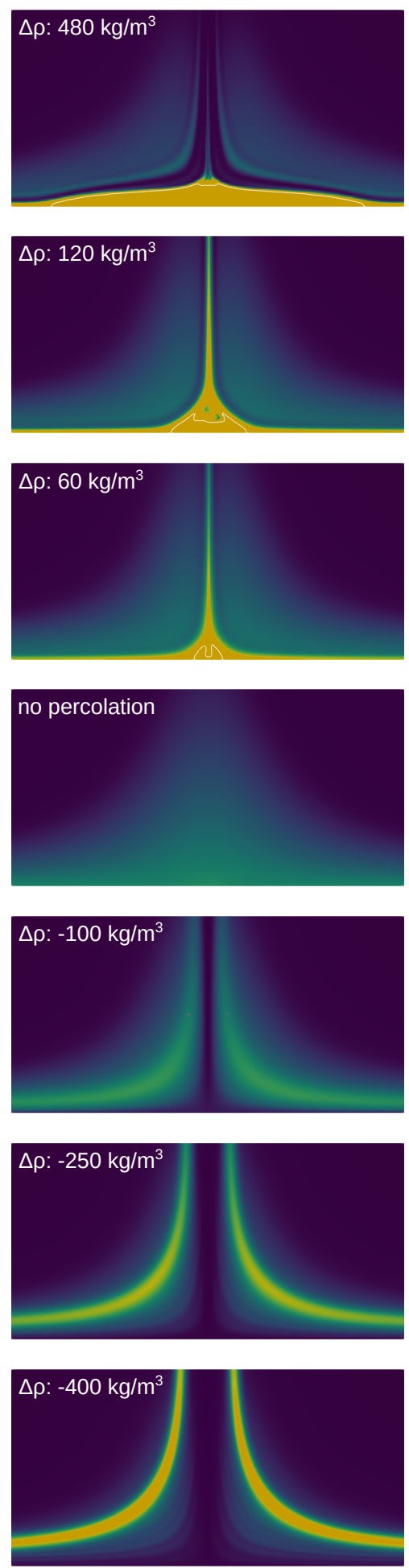

Porosity

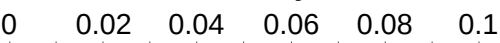

Figure 10. Morphology of partial melt zones for different melt densities. Density differences between melt and solid for the first melt that forms are indicated in each panel. The white contour indicates a porosity of $30 \%$ (disaggregation). All panels show a $100 \mathrm{~km} \times 50 \mathrm{~km}$ clip of the model centered around the partial melt zone, $150 \mathrm{Myr}$ after the start of melt migration, except for the 'no percolation' panel, which shows a model without melt motion. 
forming a region of high melt fraction (varying between $15 \%$ up to $90 \%$ within this region). Because the upwards drag of the plume balances the downward segregation of melt, this basal region of partial melt does not grow over time (see also Supplementary Video 2). Note that even though these models are consistent with the thermal state of the Earth (there is no rapidly growing magma layer at the base of the mantle), their morphology is quite different from the current expected shape for ULVZs. The zones in this model do not necessarily have a large aspect ratio, they reach the disaggregation threshold within the small basal region of large melt fraction (white outlines in Figure $10, \Delta \rho=120 \mathrm{~kg} / \mathrm{m}^{3}$, $\Delta \rho=60 \mathrm{~kg} / \mathrm{m}^{3}$ ), and they do not have very flat tops or clearly defined edges, all features that have been reported from seismic studies.

If melt is less dense than the solid, it segregates upwards instead of downwards, and it moves fastest in the parts of the mantle where most melt is generated (i.e. the hottest regions). Consequently, melt drains almost completely from the base of the plume conduit, and a stable region of partial melt forms at the edges of the melting zone (see also Supplementary Video 3). This stable zone of melt acts as a channel that melt can flow along towards the central axis of the plume, similar to the high-porosity decompaction channel suggested to exist at the base of the lithospheric plates below mid-ocean ridges (e.g. Sparks \& Parmentier, 1991). The lower the melt density, the faster the upward flow of melt. This leads to thinner bands of partial melt at the edges of the melting zone that contain larger fractions of partial melt, and have sharper gradients in porosity (Figure 10, $\Delta \rho \leq-100 \mathrm{~kg} / \mathrm{m}^{3}, \Delta \rho=-250$ $\mathrm{kg} / \mathrm{m}^{3}, \Delta \rho=-400 \mathrm{~kg} / \mathrm{m}^{3}$ ). Note the sharpness of the top of the partial melt zone also depends on the permeability, which is fixed to our baseline value for this model series (see Table 1), a much lower value than assumed for melt transport in the upper mantle (see Section 2.1.5). For larger permeabilities, a sharp top of the partial melt zone may form for smaller density differences between melt and solid than predicted in our models.

\subsubsection{Chemical heterogeneities introduced by the melting process}

The melting process also creates chemical heterogeneities in our models. We will describe these heterogeneities in terms of the parameters we used in the melting model, namely the molar fraction of the iron-bearing endmember (see Section 2.2.1). For simplicity, we will use the terms iron-rich (or ironpoor) in reference to the background iron content. However, we avoid making quantitative statements about melt composition, because the empirical modifications that we make to the melt density in our models may represent unmodelled compositional differences.

The melt generated in our models is more iron-rich than the source material, so the fraction of iron will increase in regions where the melt migrates to (and freezes), and the residual that is left behind will be poor in iron. The nature and scale of chemical heterogeneity generated depends on the 

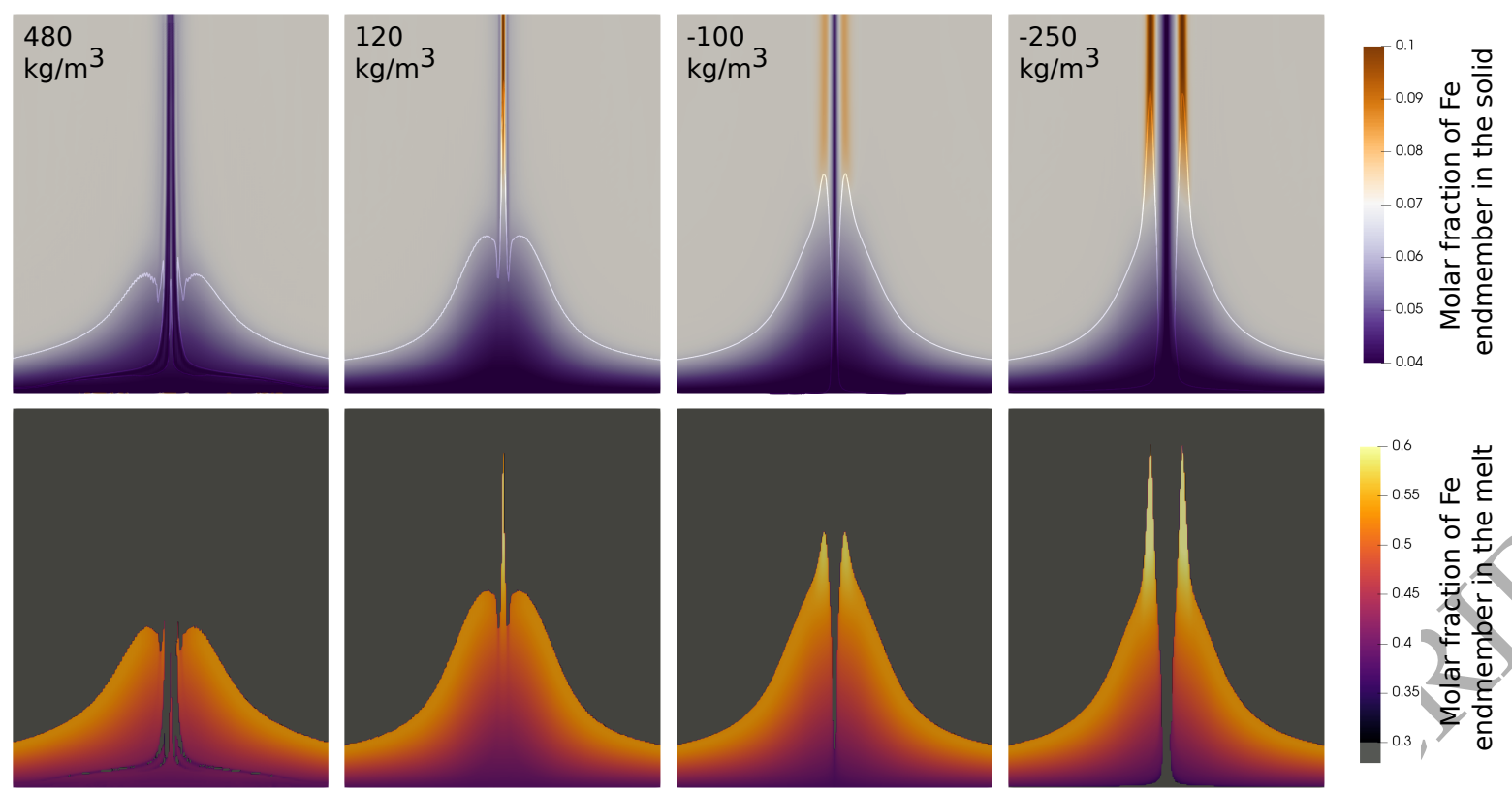

Decreasing melt density

Figure 11. Compositional heterogeneities created by the melting process for different melt densities. Density differences between melt and solid for the first melt that forms are indicated in each panel. The solid white line in the top row indicates the boundary between regions with and without melt (marking a porosity of $1 \%$ ). All panels show a $100 \mathrm{~km} \times 120 \mathrm{~km}$ clip of the model centered around the partial melt zone, $150 \mathrm{Myr}$ after the start of melt migration.

melt density (see Figure 11). If melt is very dense and accumulates in a growing melt layer at the $\mathrm{CMB}$, only the iron-poor residual is entrained in the plume. Conversely, if melt and solid densities are closer to each other, the plume carries both melt and residuum upwards. Melt that is denser than the solid initially segregates downwards and is entrained in the center of the plume. Consequently, the rising plume will carry iron-rich material along its axis, with a ring of material depleted in iron surrounding the center. Melt that is less dense than the solid segregates upwards and travels towards the plume conduit along high-permeability channels, so that the center of the plume is depleted in iron, and a ring around it is enriched in iron. The lower the density of the melt (the faster it can segregate), the stronger the difference in iron content between these different regions. The horizontal extent of the heterogeneities in the rising plume conduit is on the order of a few kilometers. For the 'no percolation' case, no chemical heterogeneities are generated.

In principle, this means that geochemical observations should be able to provide evidence for either of these scenarios, because the distribution of iron-rich and iron-poor material is different for the cases with dense melt on the one side, and melt that is less dense on the other side. However, we anticipate that in practice, it will be hard to measure these chemical differences, since they occur 

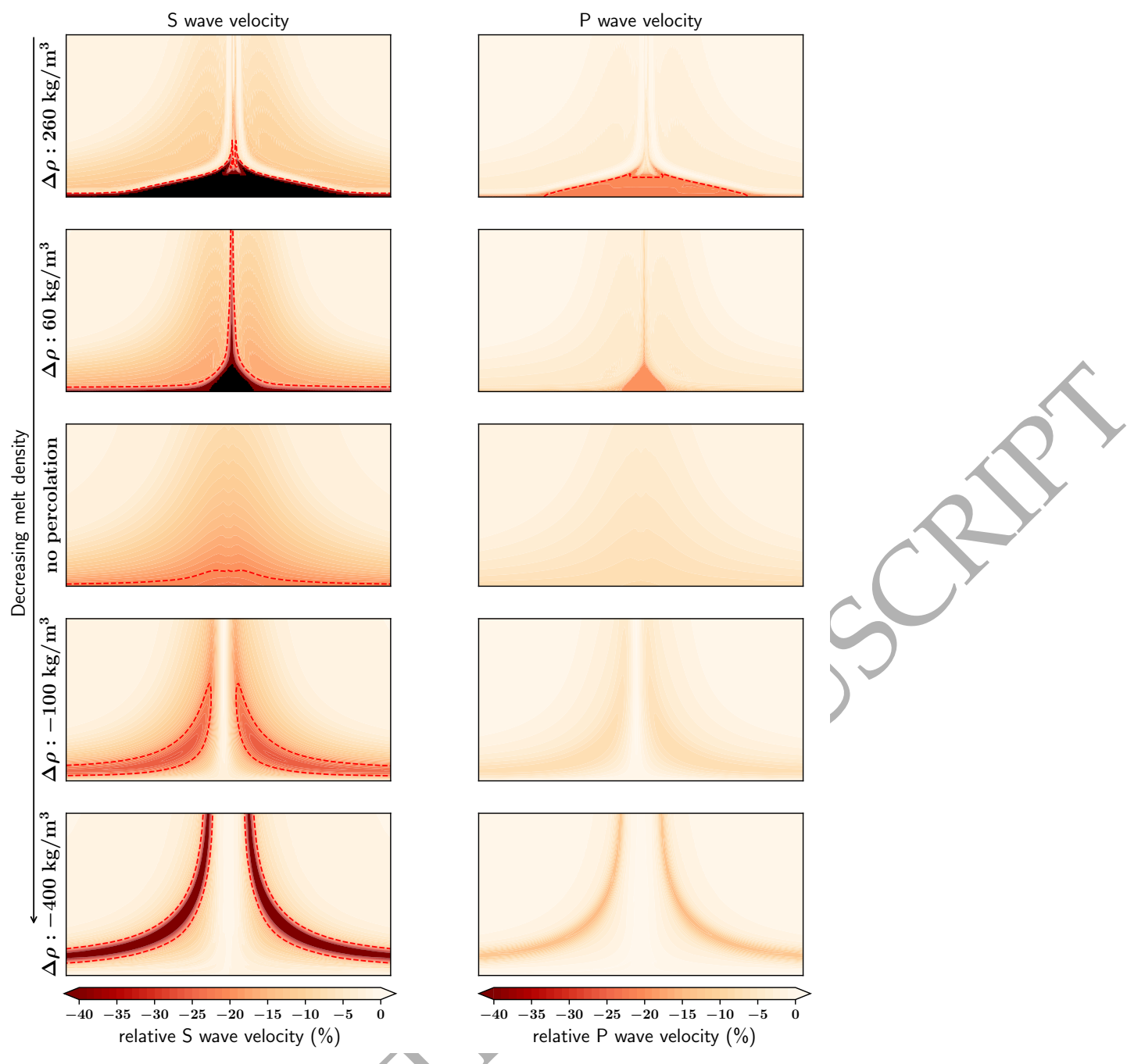

Figure 12. Estimated seismic velocities deviations for models with different melt densities. Values are shown with respect to a $V_{S}$ of $7.1 \mathrm{~km} / \mathrm{s}$ and a $V_{P}$ of $13.9 \mathrm{~km} / \mathrm{s}$. Red dashed lines show contours of $-20 \%$ velocity reduction. $100 \%$ velocity reduction is shown in black. All panels show a $100 \mathrm{~km} \times 50 \mathrm{~km}$ clip of the model centered around the partial melt zone, $150 \mathrm{Myr}$ after the start of melt migration, except for the 'no percolation' panel, which shows a model without melt motion.

on very small length scales, which may be further stretched out during plume ascent, they would be modified by melting near the surface, and it is not clear how the melting process near the core-mantle boundaries would affect the fractionation of other elements.

\subsection{Synthetic Seismic Velocities}

To produce models that might look like observed ULVZs, we increase the amount of melt present by further reducing the melting temperature by $50 \mathrm{~K}$ (to $-650 \mathrm{~K}$ ). This reduction increases melt content, but does not change the fundamental dynamics for varying melt density. Plots for the porosity 
variations are shown in Supplementary Figure A4. Figure 12 shows the seismic velocities estimated for models with varying melt density. Velocities are a result of the combination of the variation in melt, composition, and temperature in the models as described in Section 2.4. Particularly the effect of melt presence on the seismic velocities is approximated, as it depends strongly on the geometry the melt takes in the interstitial pore spaces.

For the cases with negatively buoyant melt $\left(\Delta \rho=+60 \mathrm{~kg} / \mathrm{m}^{3}\right.$ and $\left.+260 \mathrm{~kg} / \mathrm{m}^{3}\right)$ a melt layer develops at the CMB, which is thickened at the base of the mantle plume. For the $+260 \mathrm{~kg} / \mathrm{m}^{3}$ case this layer grows rapidly, while $\Delta \rho=+60 \mathrm{~kg} / \mathrm{m}^{3}$ case the melt volume is in steady state (see Figure 9). There is no seismic evidence for a global melt layer, or one at the base of ULVZs. Such a layer would naturally not be visible to S-waves, as it is indistinguishable from the liquid outer core, and the morphology of the layer would therefore appear as topography on the CMB. For P-waves, however, we predict velocity reductions on the order of $\sim 20 \%$, which still shows significant contrast with the outer core, where the velocity at the top is $\sim 45 \%$ slower than the mantle. These zones would therefore be more easily detected in $\mathrm{P}$ waves than in $\mathrm{S}$ waves, which is incongruous with the majority of ULVZ studies detecting them using S-waves and observed $\mathrm{P}$ wave velocity reductions generally on the order of $-10 \%$ (Yu \& Garnero, 2018).

The model with 'no percolation' shows gradual velocity variations and lacks a sharp top. The $d V s: d V p$ ratio reaches $\sim 3: 1$ for the largest melt fractions present in the model. Shear wave velocity reductions of more than $20 \%$ are limited to the very base, extending up to $5 \mathrm{~km}$ at the centre of the plume.

The cases with positively buoyant melt $\left(\Delta \rho=-100 \mathrm{~kg} / \mathrm{m}^{3}\right.$ and $\left.-400 \mathrm{~kg} / \mathrm{m}^{3}\right)$ result in global slow, melt-rich zones separated from the CMB. The shear velocity reductions in these zones reach $-26 \%$ and $-56 \%$ for the $-100 \mathrm{~kg} / \mathrm{m}^{3}$ and $-400 \mathrm{~kg} / \mathrm{m}^{3}$ cases, respectively, and $d V s: d V p$ ratios range around 3:1 to 4:1. The melt zones are dragged up in the plume on either side, velocities of $-20 \%$ on either side reach $30 \mathrm{~km}$ and $130 \mathrm{~km}$ above the CMB for the $-100 \mathrm{~kg} / \mathrm{m}^{3}$ and $-400 \mathrm{~kg} / \mathrm{m}^{3}$ cases, respectively. The widths of the low velocity bands, defined by the $-20 \%$ contours, vary from about 5 to $10 \mathrm{~km}$. The edges of the bands are sharp; the velocity drops there from several percent to several tens of percent over 1-2 kilometres.

\section{DISCUSSION}

\subsection{Requirements for partial melt presence in the lowermost mantle}

As discussed briefly in the methodology, the combination of the melting model taken from Boukaré et al. (2015) and geophysical estimates of CMB temperature suggest that the lowermost mantle does 
not melt at the present day. The most important requirement for melting is therefore that either this melting model overestimates melting temperatures, or that geophysical estimates underestimate CMB temperatures (or both).

A second requirement is that melts generated do not react rapidly to form metasomatized solids. This might be the case, for example, if mafic materials such as MORB were to melt (Andrault et al., 2014; Pradhan et al., 2015). In this case, we would expect the highly silicic melt to react with ferropericlase in ultramafic materials to form bridgmanite.

A third requirement to form partial melt pockets and avoid a global layer of $100 \%$ melt, is that the melt is either trapped in the solid due to high interfacial energies (forming large dihedral angles), or is at least not much denser than the residual solid. The strong iron enrichment in the melts in the baseline model results in a melt that is some $800 \mathrm{~kg} / \mathrm{m}^{3}$ denser than the surrounding solid, which favours rapid separation into a $100 \%$ melt layer at the base of the mantle.

\subsection{Comparison to seismically observed ULVZs}

When comparing to seismic models of ULVZs, one limitation is that studies regularly assume ULVZs to be internally homogeneous to limit the number of parameters to constrain. A small number of studies include internal variations within the ULVZ (Rost et al., 2006; Pachhai et al., 2015; Zhao et al., 2017; Li et al., 2021), but their conclusions vary in terms of velocity reducing or increasing towards the $\mathrm{CMB}$. For this reason, and the fact that our velocity reductions are estimated by assuming the melt geometry, we restrict ourselves to a qualitative comparison. A more rigorous approach, well beyond the scope of this study, would be to create axisymmetric 3D models of these 2D slices and run full-waveform simulations through them. Common seismic analyses can then be applied to see if seismic waves observe any of these models as a 'typical ULVZ'. This approach would provide a more rigorous test of the sensitivity of different seismic phases to the 5-10 km wide melt zones observed in the models with positively buoyant melt. The synthetics for 3D models up to the frequencies required remain computationally expensive even though recent improvements have been made (Leng et al., 2020).

Reported ULVZs vary largely in width, height and velocity reduction, but studies agree that the anomalies are localized (Yu \& Garnero, 2018), with a number of regional studies noting the absence of ULVZs (e.g. Rost et al., 2010; Vanacore et al., 2016; Thorne et al., 2020). Our models predict a global layer of melt, either on the $\mathrm{CMB}$ or just above the $\mathrm{CMB}$, which thickens or warps upwards at the base of the mantle plume. Cold downwellings, which are not included in our simulations, would further decrease the thickness of this partial melt layer at their locations. It remains possible that this global layer of melt lies beneath the seismic threshold of detection in most regions. Otherwise, the ULVZs 
observed cannot be the result of present-day melting alone, and compositional variation needs to be invoked to explain the observations. Solid-state compositional variations can also modify the melting temperature and create melt in the first place.

Our models do not explain particularly broad ULVZs that are $800-1000 \mathrm{~km}$ in width and have been speculated to lie at the base of mantle plumes (e.g. Cottaar \& Romanowicz, 2012; Thorne et al., 2013; Yuan \& Romanowicz, 2017). In our models the localised anomaly due to the upwelling plume is only tens of kilometers in width. The width of the plume conduit in our models is a direct result of some of the parameter choices we have made: all parameters that influence the Rayleigh number (most importantly, the mantle viscosity) would also influence the length scale of upwellings. In particular, since our results have shown that parameters related to magma dynamics do not have a major influence on the morphology of the partial melt zones, we expect that ULVZ shapes would look very similarin models that have different mantle viscosities but the same Rayleigh number (with the size of the model domain scaled accordingly: a change of a factor of 2 in the length scale corresponding to a factor of 8 in viscosity). This means that the large uncertainties in the value of the lowermost mantle viscosity leaves room for changing the length-scaling of the model results. The other important factor is the chemical composition of mantle plumes. We know that mantle plumes carry heterogeneous material towards the surface, but for simplicity, our models assume a homogeneous initial mantle composition. It has been shown that mantle plumes that entrain dense material, such as recycled oceanic crust or primordial iron-rich material, have a wider plume tail than these purely thermal plumes (e.g., Dannberg $\&$ Sobolev, 2015). In addition, this composition would reduce the melting temperature inside the plume compared to the background mantle. All of these factors could contribute to a wider lateral extent of partial melt zones at the base of plumes.

Other observed ULVZs, however, are thought to be $<100 \mathrm{~km}$ in width (Yu \& Garnero, 2018). The studies of Rost et al. $(2005,2006)$ report a ULVZ using ScP phases with width of $\sim 50 \mathrm{~km}$ and a sharp top at $8.5 \mathrm{~km}$ with velocity reductions of $-24 \%$ in $d V_{S}$ and $-8 \%$ in $d V_{P}$. These studies use the observed $d V_{S}: d V_{R}$ of 3:1 to support a partial-melt hypothesis. The features observed agree best with our models with positively buoyant melt, although where the melt extends higher in the centre in our models, the zone does not show a flat top. These studies, along with several others (e.g. Vanacore et al., 2016), also report a $+10 \% \rho$ jump required by their data, which is inconsistent with our positively buoyant melt case, and would have to be remedied by the inclusion of solid-state compositional variations. Rost et al. (2006) show their data is most consistent with a positive velocity gradient towards the $\mathrm{CMB}$, a feature observed in our models with positively buoyant melt. It should be noted that estimates of the density and the velocity gradient within ULVZs are derived from the 
observed amplitudes of seismic phases, which are more difficult to interpret than travel times (e.g. Jenkins et al., 2021) .

\subsection{Core-mantle chemical interaction}

Our study treats the CMB as an impermeable membrane through which only heat can flow. In reality, chemical exchange is also likely. Some studies propose that the bulk outer core is undersaturated in light elements, which would result in net dissolution of several elements (probably silicon, oxygen and iron) from the mantle into the core at the CMB (Buffett, 2015). Other studies suggest that the outer core is saturated in light elements, and is therefore exsolving a buoyant phase as it cools, possibly $\mathrm{SiO}_{2}$ or a silicate melt (Helffrich et al., 2020). Core-mantle interaction may impact a core isotopic signature into plumes which originated at the base of the mantle. This signature may be present in plume-related lavas, although the signature remains controversial (Brandon \& Walker, 2005; Buffett, 2015).

Core-mantle interaction should therefore be considered in explanations of ULVZ generation. Chemical reactions between core, mantle and CMB melts could change melt composition and volume and therefore influence the observed characteristics of ULVZs. Interaction of those deep melts with the solid mantle could in turn affect the compositions of plume-derived melts.

Given the present uncertainties, we leave the intricacies of core-mantle interaction for other studies. However, we note that in order for ULVZs to be composed of silicate melts exsolved from the core (Helffrich et al., 2020), those melts would have to be both positively buoyant relative to the mantle (so that they don't form a pure melt layer at the CMB), and also not highly reactive with the mantle (in order to generate a thick enough mush layer to be observed).

\subsection{Lowermost mantle melting in Earth's deep past}

Our study has focused on present-day melting processes as a mechanism to create ULVZs, but the same processes are equally applicable to other periods in Earth's history. In the Archean, mantle temperatures were higher, as attested to by komatiitic lavas (Grove \& Parman, 2004), and the mantle was less well-mixed. Both of these factors would have encouraged the formation of deep mantle melts.

As the Earth cooled, melts could have either reacted with the mantle and/or crystallized. If meltmantle reaction was efficient then the total melt volume would have decreased without forming cumulate phases. This is similar to the situations modelled in our study, but rather than melting causing net FeO-depletion of the solid mantle, the solid mantle would scavenge $\mathrm{FeO}$ from existing melts, enriching plumes. Conversely, if melt-mantle reaction was sluggish compared with the rate of cooling-driven disequilibration, melt layers could form crystal cumulates either at their tops or bases. If ULVZs are frozen melts (Labrosse et al., 2007; Boukaré et al., 2015), perhaps dominated by FeO-rich ferroperi- 
clase (Wicks et al., 2017), the cumulate sequences must have been sufficiently dense and inviscid to avoid entrainment by the solid mantle.

\section{CONCLUSIONS}

We have developed coupled geodynamic and thermodynamic models of deep mantle melting to test the hypothesis that partial melt above the CMB explains the presence of ULVZs. By simulating the thermodynamic and dynamical evolution of zones of partial melt near the CMB, our models make predictions about the shape, stability and melt distribution within these regions, and the corresponding effect on seismic velocities and compositional heterogeneity in plumes. For partial melting to occur in pyrolite, we have to generously reduce the melting temperature compared to published thermodynamic predictions in simple chemical systems (Baron et al., 2017; de Koker et al., 2013; Boukaré etal., 2015). Additionally, our models predict that it is challenging to create stable and elevated pockets of partial melt. For a wide range of plausible permeabilities and viscosities of the partially molten region, melt is too dense to be stirred into convective flow and instead sinks down to form a completely molten layer, which is inconsistent with observations of ULVZs. Only if melt is less dense than the solid or almost neutrally buoyant - having a density contrast of about $1 \%$ or less - melt can stay suspended in the partial melt zone. In these cases, seismic velocities would be reduced in a cone at the base of the plume.

For slightly negatively buoyant melt, the largest velocity reduction occurs at the CMB, around the center of the plume conduit, and there is a gradual change in seismic velocities at the top of the partial melt zone. Conversely, for buoyant melt, the strongest velocity reduction occurs at the top of the partial melt zone and the change in velocities occurs over a much smaller distance. The lower the melt density, and the more melt is generated, the sharper the top of the partial melt zone. A substantial amount of partial melt is needed to reproduce the strong seismic velocity reductions observed in ULVZs: Our models predict shear velocity reductions of $-26 \%$ for the presence of $10 \%$ of melt.

Some seismic observations of ULVZs, such as sharp tops and stronger shear wave velocity reductions compared to $\mathrm{P}$ waye velocity reductions, are consistently reflected in our model of positively buoyant melt. Other observations, such as the localised occurrence of ULVZs, their large aspect ratios, and their relative positive density, are not reproduced in any of our models independent of melt buoyancy. In addition, positively buoyant melt at the CMB is unlikely based on most estimates of melt properties at deep mantle pressures. We therefore suggest observed ULVZs do not result purely from melting of average present-day mantle material at the CMB. Our study does not rule out that compositional variations in the melt source material could explain reduced melting temperatures, produce less dense melts, widen plume bases, and create the wide, localised ULVZs observed. Further research 
could clarify if partial melt from a compositionally distinct source would be consistent with ULVZs, or their seismically observed distribution and shape can be explained by chemical heterogeneities alone.

\section{ACKNOWLEDGMENTS}

The authors thank Beñat Oliveira and an anonymous reviewer for their helpful comments, which greatly helped to improve this manuscript.

This project has received funding from the European Research Council (ERC) under the European Union's Horizon 2020 research and innovation programme (grant agreement No. 804071 ZoomDeep). JD and RG were partially supported by the Computational Infrastructure for Geodynamics initiative through NSF EAR-1550901 and by the NSF grant EAR-1925677. JD gratefully acknowledges the support of the Deep Carbon Observatory. RM is funded by a UKSA Aurora Postdoctoral Fellowship (ST/R001332/1).

The authors acknowledge University of Florida Research Computing (http://researchcomputing . ufl. edu) for providing computational resources and support that have contributed to the research results reported in this publication. Additional compute time for the computations shown in Section 3.1 was also provided by CIG on Stampede2. The authors acknowledge the Texas Advanced Computing Center (TACC, http://www. tacc. utexas . edu) at The University of Texas at Austin for providing high-performance computing resources that have contributed to the research results reported within this paper.

All authors were involved in the design of the study. RM developed the thermodynamic and melt models and implemented them in BurnMan. JDand RG implemented the methods in ASPECT and JD ran the geodynamic models. SC computed the seismic velocities. All authors interpreted the results and wrote the paper.

\section{DATA AVAILABILITY}

All software and data used to generate the results and figures in this manuscript are freely available. The specific files and instructions are published as a Zenodo data package (Gassmoeller et al., 2021) and include the source code and links to the GitHub versions of both BurnMan and ASPECT as well as the input files to compute the models and plotting scripts to generate the figures. 


\section{References}

Abe, Y., 1995. Basic equations for evolution of partially molten mantle and core, The Earth's central part: its structure and dynamics, pp. 215-235.

Alfe, D., Kresse, G., \& Gillan, M., 2000. Structure and dynamics of liquid iron under Earth's core conditions, Physical Review B, 61(1), 132.

Andrault, D., Petitgirard, S., Lo Nigro, G., Devidal, J.-L., Veronesi, G., Garbarino, G., \& Mezouar, M., 2012. Solid-liquid iron partitioning in Earth's deep mantle, Nature, 487(7407), 354-357.

Andrault, D., Pesce, G., Bouhifd, M. A., Bolfan-Casanova, N., Hénot, J.-M., \& Mezouar, M., 2014. Melting of subducted basalt at the core-mantle boundary, Science, 344(6186), 892-895.

Anzellini, S., Dewaele, A., Mezouar, M., Loubeyre, P., \& Morard, G., 2013. Melting of iron at Earth's inner core boundary based on fast X-ray diffraction, Science, 340(6131), 464-466.

Bangerth, W., Dannberg, J., Gassmoeller, R., \& Heister, T., 2019. Aspect v2.1.0.

Barcilon, V. \& Lovera, O. M., 1989. Solitary waves in magma dynamics, Journal of Fluid Mechanics, 204, 121-133.

Barcilon, V. \& Richter, F. M., 1986. Nonlinear waves in compacting media, Journal of Fluid Mechanics, 164, 429-448.

Baron, M. A., Lord, O. T., Myhill, R., Thomson, A. R., Wang, W., Trønnes, R. G., \& Walter, M. J., 2017. Experimental constraints on melting temperatures in the mgo-sio2 system at lower mantle pressures, Earth and Planetary Science Letters, 472, 186-196.

Batchelor, G. K., 1967. An introduction to fluid dynamics, (1967), Cambridge,: UP xviii, 615.

Berryman, J. G., 2000. Seismic velocity decrement ratios for regions of partial melt in the lower mantle, Geophysical research letters, 27(3), 421-424.

Boehler, R., 2000. High-pressure experiments and the phase diagram of lower mantle and core materials, Reviews of Geophysics, 38(2), 221-245.

Boukaré, C.-E., Ricard, Y., \& Fiquet, G., 2015. Thermodynamics of the MgO-FeO-SiO2 system up to $140 \mathrm{GPa}$ : Application to the crystallization of Earth's magma ocean, Journal of Geophysical Research: Solid Earth, 120(9), 6085-6101.

Bower, D. J., Wicks, J. K., Gurnis, M., \& Jackson, J. M., 2011. A geodynamic and mineral physics model of a solid-state ultralow-velocity zone, Earth Planet. Sci. Lett., 303(3-4), 193-202.

Brandon, A. D. \& Walker, R. J., 2005. The debate over core-mantle interaction, Earth and Planetary Science Letters, 232(3-4), 211-225.

Buffett, B., 2015. 8.08 - core-mantle interactions, in Treatise on Geophysics (Second Edition), pp. 213 - 224, ed. Schubert, G., Elsevier, Oxford, second edition edn.

Buffett, B. A., Garnero, E. J., \& Jeanloz, R., 2000. Sediments at the top of Earth's core, Science, 
290(5495), 1338-1342.

Caracas, R., Hirose, K., Nomura, R., \& Ballmer, M. D., 2019. Melt-crystal density crossover in a deep magma ocean, Earth and Planetary Science Letters, 516, 202 - 211.

Cottaar, S. \& Li, Z., 2019. A large ultra-low velocity zone at the potential base of the Galapagos plume, in AGU Fall Meeting Abstracts, vol. 2019, pp. DI33A-04.

Cottaar, S. \& Romanowicz, B., 2012. An unusually large ULVZ at the base of the mantle near Hawaii, Earth and Planetary Science Letters, 355-356, 213-222.

Cottaar, S., Heister, T., Rose, I., \& Unterborn, C., 2014. BurnMan: A lower mantle mineral physics toolkit, Geochemistry, Geophysics, Geosystems, 15(4), 1164-1179.

Dannberg, J. \& Heister, T., 2016. Compressible magma/mantle dynamics: 3-D, adaptive simulations in ASPECT, Geophysical Journal International, 207(3), 1343-1366.

Dannberg, J. \& Sobolev, S. V., 2015. Low-buoyancy thermochemical plumes resolve controversy of classical mantle plume concept, Nature communications, $\mathbf{6}$.

Dannberg, J., Eilon, Z., Faul, U., Gassmöller, R., Moulik, P., \& Myhill, R., 2017. The importance of grain size to mantle dynamics and seismological observations, Geochemistry, Geophysics, Geosystems, $\mathbf{1 8}(8)$.

Dannberg, J., Gassmöller, R., Grove, R., \& Heister, T., 2019. A new formulation for coupled magma/mantle dynamics, Geophysical Journal International, 219(1), 94-107.

de Koker, N., Karki, B. B., \& Stixrude, L., 2013. Thermodynamics of the $\mathrm{MgO}_{-} \mathrm{SiO}_{2}$ liquid system in Earth's lowermost mantle from first principles, Earth and Planetary Science Letters, 361, 58-63.

Dobson, D. P. \& Brodholt, J. P., 2005. Subducted banded iron formations as a source of ultralowvelocity zones at the core-mantle boundary, Nature, 434(7031), 371-374.

Dziewonski, A. M. \& Anderson, D. L., 1981 Preliminary reference Earth model, Physics Of The Earth And Planetary Interiors, 25(4), 297-356.

Frost, D. \& Myhill, R., 2015, Chemistry of the Lower Mantle, in Deep Earth: Physics and Chemistry of the Lower Mantle and Core, Wiley Online Library.

Frost, D. J. \& Langénhorst, F., 2002. The effect of $\mathrm{Al}_{2} \mathrm{O}_{3}$ on Fe-Mg partitioning between magnesiowüstite and magnesium silicate perovskite, Earth and Planetary Science Letters, 199, 227-241.

Funamori, N., 2004. Exploratory studies of silicate melt structure at high pressures and temperatures by in situ X-ray diffraction, Journal of Geophysical Research Atmospheres, 109(B3).

Funamori, N. \& Sato, T., 2010. Density contrast between silicate melts and crystals in the deep mantle: An integrated view based on static-compression data, Earth and Planetary Science Letters, 295(3-4), 435-440.

Gassmoeller, R., Dannberg, J., Myhill, R., \& Cottaar, S., 2021. dataset: The morphology, evolution 
and seismic visibility of partial melt at the core-mantle boundary: Data and software (Version 2.0.0). Zenodo. http://doi.org/10.5281/zenodo.4734715.

Grove, T. \& Parman, S., 2004. Thermal evolution of the Earth as recorded by komatiites, Earth and Planetary Science Letters, 219(3), 173 - 187.

Hansen, S. E., Carson, S. E., Garnero, E. J., Rost, S., \& Yu, S., 2020. Investigating ultra-low velocity zones in the southern hemisphere using an Antarctic dataset, Earth and Planetary Science Letters, 536, 116142.

Heister, T., Dannberg, J., Gassmöller, R., \& Bangerth, W., 2017. High accuracy mantle convection simulation through modern numerical methods-II: realistic models and problems, Geophysical Journal International, 210(2), 833-851.

Helffrich, G., Hirose, K., \& Nomura, R., 2020. Thermodynamical Modeling of Liquid Fe-Si-MgO:Molten Magnesium Silicate Release From the Core, Geophysical Research Letters, 47(21).

Hernlund, J. W. \& Bonati, I., 2019. Modeling ultralow velocity zones as a thin chemically distinct dense layer at the core-mantle boundary, Journal of Geophysical Research-Solid Earth, 124(8), $7902-7917$.

Hernlund, J. W. \& Jellinek, A. M., 2010. Dynamics and structure of a stirred partially molten ultralow-velocity zone, Earth and Planetary Science Letters, 296(1-2), 1-8.

Hernlund, J. W. \& Tackley, P. J., 2007. Some dynamical consequences of partial melting in Earth's deep mantle, Physics of the Earth and Planetary Interiors, 162(1-2), 149-163.

Hernlund, J. W., Thomas, C., \& Tackley, P. J., 2005. A doubling of the post-perovskite phase boundary and structure of the Earth's lowermost mantle, Nature, 434(7035), 882-886.

Hier-Majumder, S., 2014. Melt redistribution by pulsed compaction within UltraLow Velocity Zones, Physics of the Earth and Planetary Interiors, 229, 134-143.

Hier-Majumder, S. \& Drombosky, T W., 2016. Coupled flow and anisotropy in the UltraLow Velocity Zones, Earth and Planetary Science Letters, 450, 274-282.

Hier-Majumder, S., Ricard, Y., \& Bercovici, D., 2006. Role of grain boundaries in magma migration and storage, Earth and Planetary Science Letters, 248(3-4), 735-749.

Holland, T. J., Hudson, N. F., Powell, R., \& Harte, B., 2013a. New Thermodynamic Models and Calculated Phase Equilibria in NCFMAS for Basic and Ultrabasic Compositions through the Transition Zone into the Uppermost Lower Mantle, Journal of Petrology, 54(9), 1901-1920.

Holland, T.J. B. \& Powell, R., 2011. An improved and extended internally consistent thermodynamic dataset for phases of petrological interest, involving a new equation of state for solids, Journal of Metamorphic Geology, 29(3), 333-383.

Holland, T. J. B., Hudson, N. F. C., Powell, R., \& Harte, B., 2013b. New Thermodynamic Models 
and Calculated Phase Equilibria in NCFMAS for Basic and Ultrabasic Compositions through the Transition Zone into the Uppermost Lower Mantle, Journal of Petrology, 54(9), 1901-1920.

Idehara, K., 2011. Structural heterogeneity of an ultra-low-velocity zone beneath the Philippine Islands: Implications for core-mantle chemical interactions induced by massive partial melting at the bottom of the mantle, Physics of the Earth and Planetary Interiors, 184(1-2), 80-90.

Irifune, T., Shinmei, T., Mccammon, C. A., Miyajima, N., Rubie, D. C., \& Frost, D. J., 2010. Iron Partitioning and Density Changes of Pyrolite in Earth's Lower Mantle, Science, 327(5962), 193-195.

Jellinek, A. M. \& Manga, M., 2004. Links between long-lived hot spots, mantle plumes, D”, and plate tectonics, Reviews of Geophysics, 42(3).

Jenkins, J., Mousavi, S., Li, Z., \& Cottaar, S., 2021. A high-resolution map of Hawaiian ULVZ morphology from $\mathrm{ScS}$ phases, Earth and Planetary Science Letters, in revision.

Katz, R. F., 2008. Magma dynamics with the enthalpy method: Benchmark solutions and magmatic focusing at mid-ocean ridges, Journal of Petrology, 49(12), 2099-2121.

Keller, T. \& Katz, R. F., 2016. The role of volatiles in reactive melt transport in the asthenosphere, Journal of Petrology, 57(6), 1073-1108.

Keller, T. \& Suckale, J., 2019. A continuum model of multi-phase reactive transport in igneous systems, Geophysical Journal International, 219(1), 185-222.

Keller, T., May, D. A., \& Kaus, B. J. P., 2013. Numerical modelling of magma dynamics coupled to tectonic deformation of lithosphere and crust, Geophysical Journal International, 195(3), 14061442 .

Kim, D., Lekić, V., Ménard, B., Baron, D., \& Taghizadeh-Popp, M., 2020. Sequencing seismograms: A panoptic view of scattering in the core-mantle boundary region, Science, 368(6496), 1223-1228. Kimura, T., Ohfuji, H., Nishi, M., \& Irifune, T., 2017. Melting temperatures of $\mathrm{MgO}$ under high pressure by micro-texture analysís, Nature Communications, $\mathbf{8}(1)$.

Knittle, E. \& Jeanloz, R., 1989. Simulating the core-mantle boundary: An experimental study of highpressure reactions between silicates and liquid iron, Geophysical Research Letters, 16(7), 609-612. Kohlstedt, L. \& Hansen, L., 2015. Constitutive equations, rheological behavior, and viscosity of rocks, in "Mineral physics"(ed. Price, GD, Stixrude, L.), Treatise on Geophysics, 2.

Komabayashi, T., 2014. Thermodynamics of melting relations in the system $\mathrm{Fe}-\mathrm{FeO}$ at high pressure: Implications for oxygen in the Earth's core, Journal of Geophysical Research (Solid Earth), 119, $4164-4177$.

Kono, Y., Shibazaki, Y., Kenney-Benson, C., Wang, Y., \& Shen, G., 2018. Pressure-induced structural change in $\mathrm{MgSiO} 3$ glass at pressures near the Earth's core-mantle boundary, Proceedings of the National Academy of Sciences, 115(8), 1742-1747. 
Labrosse, S., Hernlund, J., \& Coltice, N., 2007. A crystallizing dense magma ocean at the base of the Earth's mantle, Nature, 450(7171), 866-869.

Lay, T., Hernlund, J., \& Buffett, B. A., 2008. Core-mantle boundary heat flow, Nature Geoscience, 1(1), 25-32.

Leng, K., Korenaga, J., \& Nissen-Meyer, T., 2020. 3-D scattering of elastic waves by small-scale heterogeneities in the Earth's mantle, Geophysical Journal International, 223(1), 502-525.

Li, M., McNamara, A. K., Garnero, E. J., \& Yu, S., 2017. Compositionally-distinct ultra-low velocity zones on Earth's core-mantle boundary, Nature communications, 8(1), 1-9.

Li, Z., Leng, K., Jenkins, J., \& Cottaar, S., 2021. Kilometer-scale structure on the core-mantle boundary at the source of the Hawaiian mantle plume, $R S$.

Liu, J., Li, J., Hrubiak, R., \& Smith, J. S., 2016. Origins of ultralow velocity zones through slabderived metallic melt, Proceedings of the National Academy of Sciences, 113(20), 5547-5551.

Mao, W. L., Mao, H.-k., Sturhahn, W., Zhao, J., Prakapenka, V. B., Meng, Y., Shu, J., Fei, Y., \& Hemley, R. J., 2006. Iron-rich post-perovskite and the origin of ultralow-velocity zones, Science, 312(5773), 564-565.

McCammon, C., Lauterbach, S., Seifert, F., Langenhorst, F., \& Van Aken, P., 2004. Iron oxidation state in lower mantle mineral assemblages, Earth and Planetary Science Letters, 222(2), 435-449.

McKenzie, D., 1984. The generation and compaction of partially molten rock, Journal of Petrology, 25(3), 713-765.

McNamara, A. K., Garnero, E. J., \& Rost, S., 2010. Tracking deep mantle reservoirs with ultra-low velocity zones, Earth and Planetary Science Letters, 299, 1-9.

Miller, K. J., Zhu, W.-1., Montési, L. G. \& Gaetani, G. A., 2014. Experimental quantification of permeability of partially molten mantle rock, Earth and Planetary Science Letters, 388, 273-282.

Millot, M., Dubrovinskaia, N., Černok, A., Blaha, S., Dubrovinsky, L., Braun, D. G., Celliers, P. M., Collins, G. W., Eggert, J. H., \& Jeanloz, R., 2015. Shock compression of stishovite and melting of silica at planetary interior conditions, Science, 347(6220), 418-420.

Mitrovica, J. X. \& Fórte, A. M., 2004. A new inference of mantle viscosity based upon joint inversion of convection and glacial isostatic adjustment data, Earth Planet. Sci. Lett., 225, 177-189.

Mosenfelder, J. L. Asimow, P. D., Frost, D. J., Rubie, D. C., \& Ahrens, T. J., 2009. The MgSiO3 system at high pressure: Thermodynamic properties of perovskite, postperovskite, and melt from globalinversion of shock and static compression data, Journal of Geophysical Research: Solid Earth, 114(B1).

Muir, J. M. \& Brodholt, J. P., 2015. Elastic properties of ferropericlase at lower mantle conditions and its relevance to ULVZs, Earth and Planetary Science Letters, 417, 40-48. 
Mundl-Petermeier, A., Walker, R., Fischer, R., Lekic, V., Jackson, M., \& Kurz, M., 2020. Anomalous $182 \mathrm{~W}$ in high $3 \mathrm{He} / 4 \mathrm{He}$ ocean island basalts: Fingerprints of Earth's core?, Geochimica et Cosmochimica Acta, 271, 194-211.

Nakajima, Y., Frost, D. J., \& Rubie, D. C., 2012. Ferrous iron partitioning between magnesium silicate perovskite and ferropericlase and the composition of perovskite in the Earth's lower mantle, Journal of Geophysical Research (Solid Earth), 117(B8), B08201.

Nomura, R., Ozawa, H., Tateno, S., Hirose, K., Hernlund, J., Muto, S., Ishii, H., \& Hiraoka, N., 2011. Spin crossover and iron-rich silicate melt in the Earth's deep mantle, Nature, 473(7346), 199-202.

Ohtani, E., Litasov, K., Suzuki, A., \& Kondo, T., 2001. Stability field of new hydrous phase, $\delta$ $\mathrm{AlOOH}$, with implications for water transport into the deep mantle, Geophysical Research Letters, 28, 3991-3993.

Okamoto, T., Sumita, I., Nakakuki, T., \& Yoshida, S., 2005. Deformation of a partially molten $\mathrm{D}^{\prime \prime}$ layer by small-scale convection and the resulting seismic anisotropy and ultralow velocity zone, Physics of the Earth and Planetary Interiors, 153(1-3), 32-48.

Pachhai, S., Dettmer, J., \& Tkalčić, H., 2015. Ultra-low velocity zones beneath the Philippine and Tasman Seas revealed by a trans-dimensional Bayesian waveform inversion, Geophysical Journal International, 203(2), 1302-1318.

Panero, W. R., Pigott, J. S., Reaman, D. M., Kabbes, J. E., \& Liu, Z., 2015. Dry (mg,fe)sio 3 perovskite in the earth's lower mantle, Journal of Geophysical Research: Solid Earth, 120(2), 894-908.

Phipps Morgan, J., 2001. Thermodynamics of pressure release melting of a veined plum pudding mantle, Geochemistry, Geophysics, Geosystems, 2(4).

Pradhan, G. K., Fiquet, G., Siebert, J., Auzende, A.-L., Morard, G., Antonangeli, D., \& Garbarino, G., 2015. Melting of morb at core-mantle boundary, Earth and Planetary Science Letters, 431, $247-255$.

Rost, S., Garnero, E. J., Williams, Q., \& Manga, M., 2005. Seismological constraints on a possible plume root at the core-mantle boundary, Nature, 435(7042), 666-669.

Rost, S., Garnero, E. J., \& Williams, Q., 2006. Fine-scale ultralow-velocity zone structure from high-frequency seismic array data, Journal of Geophysical Research: Solid Earth, 111(B9).

Rost, S., Garnero, E. J., Thorne, M. S., \& Hutko, A. R., 2010. On the absence of an ultralow-velocity zone in the North Pacific, Journal of Geophysical Research: Solid Earth, 115(B4).

Rudge, J. F., 2018. Textural equilibrium melt geometries around tetrakaidecahedral grains, Proceedings of the Royal Society A: Mathematical, Physical and Engineering Sciences, 474(2212), 20170639.

Rudge, J. F., Bercovici, D., \& Spiegelman, M., 2011. Disequilibrium melting of a two phase multi- 
component mantle, Geophysical Journal International, 184(2), 699-718.

Sakamaki, T., Suzuki, A., \& Ohtani, E., 2006. Stability of hydrous melt at the base of the Earth's upper mantle, Nature, 439(7073), 192-194.

Sano, A., Ohtani, E., Kondo, T., Hirao, N., Sakai, T., Sata, N., Ohishi, Y., \& Kikegawa, T., 2008. Aluminous hydrous mineral $\delta$-AlOOH as a carrier of hydrogen into the core-mantle boundary, Geophysical Research Letters, 35(3).

Scott, T. \& Kohlstedt, D. L., 2006. The effect of large melt fraction on the deformation behavior of peridotite, Earth and Planetary Science Letters, 246(3-4), 177-187.

Sparks, D. W. \& Parmentier, E., 1991. Melt extraction from the mantle beneath spreading centers, Earth and Planetary Science Letters, 105(4), 368-377.

Spiegelman, M., 1993. Flow in deformable porous media. Part 2 numerical analysis-the relationship between shock waves and solitary waves, Journal of Fluid Mechanics, 247, 39-63.

Stacey, F. D. \& Loper, D. E., 1983. The thermal boundary-layer interpretation of $\mathrm{D}^{\prime \prime}$ and its role as a plume source, Physics of The Earth and Planetary Interiors, 33(1), 45-55.

Stixrude, L. \& Lithgow-Bertelloni, C., 2005. Thermodynamics of mantle minerals - I. Physical properties, Geophysical Journal International, 162, 610-632.

Stixrude, L. \& Lithgow-Bertelloni, C., 2011. Thermodynamics of mantle minerals - II. Phase equilibria, Geophysical Journal International, 184, 1180-1213.

Stixrude, L., de Koker, N., Sun, N., Mookherjee, M., \& Karki, B. B., 2009. Thermodynamics of silicate liquids in the deep Earth, Earth and Planetary Science Letters, 278(3-4), 226-232.

Takei, Y., 2002. Effect of pore geometry on VP/VS: From equilibrium geometry to crack, Journal of Geophysical Research: Solid Earth, 107(B2), ECV-6.

Takei, Y., 2017. Effects of partial melting on seismic velocity and attenuation: A new insight from experiments, Annual Review of Earth and Planetary Sciences, 45, 447-470.

Tateno, S., Hirose, K., \& Ohishi, Y., 2014. Melting experiments on peridotite to lowermost mantle conditions, Journal of Geophysical Research: Solid Earth, 119(6), 4684-4694.

Thorne, M. S. \& Garnero, E. J., 2004. Inferences on ultralow-velocity zone structure from a global analysis of $<\mathrm{i}>\mathrm{SPdKS}<$ /i $>$ waves, Journal of Geophysical Research: Solid Earth, 109(B8).

Thorne, M. S., Garnero, E. J., Jahnke, G., Igel, H., \& McNamara, A. K., 2013. Mega ultra low velocity zone and mantle flow, Earth and Planetary Science Letters, 364, 59-67.

Thorne, M. S., Pachhai, S., Leng, K., Wicks, J. K., \& Nissen-Meyer, T., 2020. New Candidate Ultralow-Velocity Zone Locations from Highly Anomalous SPdKS Waveforms, Minerals, 10(3), 211.

Trønnes, R., Baron, M., Eigenmann, K., Guren, M., Heyn, B., Løken, A., \& Mohn, C., 2019. Core 
formation, mantle differentiation and core-mantle interaction within earth and the terrestrial planets, Tectonophysics, 760, 165 - 198, Linking Plate Tectonics and Volcanism to Deep Earth Dynamics a tribute to Trond H. Torsvik.

Vanacore, E., Rost, S., \& Thorne, M., 2016. Ultralow-velocity zone geometries resolved by multidimensional waveform modelling, Geophysical Journal International, 206(1), 659-674.

Wicks, J. K., Jackson, J. M., Sturhahn, W., \& Zhang, D., 2017. Sound velocity and density of magnesiowüstites: Implications for ultralow-velocity zone topography, Geophysical Research Letters, 44(5), 2148-2158.

Williams, Q. \& Garnero, E. J., 1996. Seismic evidence for partial melt at the base of earth's mantle, Science, 273(5281), 1528-1530.

Wimert, J. \& Hier-Majumder, S., 2012. A three-dimensional microgeodynamic model of melt geometry in the Earth's deep interior, Journal of Geophysical Research: Solid Earth, 117(B4).

Yamazaki, D., Kato, T., Ohtani, E., \& Toriumi, M., 1996. Grain growth rates of mgsio3 perovskite and periclase under lower mantle conditions, Science, 274(5295), 2052-2054.

Yu, S. \& Garnero, E. J., 2018. Ultralow velocity zone locations: a global assessment, Geochemistry, Geophysics, Geosystems, 19(2), 396-414.

Yuan, K. \& Romanowicz, B., 2017. Seismic evidence for partial melting at the root of major hot spot plumes, Science, 357(6349), 393-397.

Zhang, L. \& Fei, Y., 2008. Melting behavior of (Mg,Fe) 0 solid solutions at high pressure, Geophysical Research Letters, 35, 13302.

Zhao, C., Garnero, E. J., Li, M., McNamara, A., \& Yu, S., 2017. Intermittent and lateral varying ULVZ structure at the northeastern margin of the Pacific LLSVP, Journal of Geophysical Research: Solid Earth, 122(2), 1198-1220.

\section{APPENDIX A: COMMONLY USED TERMS}

We provide a glossary of frequently used thermodynamic terminology in our study in Table A1.

\section{APPENDIX B: NUUMERICAL METHODS}

\section{B1 Operator splitting scheme}

Because the reaction rates $\Gamma$ depend on the values of $\phi, C_{s}, C_{f}$ (the porosity, solid and melt composition), equations (1), (2), (6) and (7) are non-linearly coupled. In addition, melting and freezing reactions happen on a much shorter time scale than advection processes. To avoid numerical instabil- 
Table A1. A glossary of some thermodynamic terms used in the manuscript.

Word Meaning

Chemical component

Ternary system

Pseudobinary system

Phase

Endmember

Solution

Ideal solution

Assemblage

Equilibrium assemblage

Solidus temperature

Liquidus temperature

Liquidus diagram

Cotectic

Binary melting loop

Molar property

Porosity
A fixed chemical composition. An independent set of components is often used to define the bounds of the chemical system of interest.

A chemical system with three independent chemical components (in this study, FeO, $\mathrm{MgO}$ and $\mathrm{SiO}_{2}$ ).

Part of a system of more than two components that can be treated approximately as a linear system of two modified components, where each of those components is a linear sum of the original set. In our paper, we treat the chemical system $\mathrm{Mg}_{0.581} \mathrm{Si}_{0.419} \mathrm{O}_{1.419-}$ $\mathrm{Fe}_{0.908} \mathrm{Si}_{0.092} \mathrm{O}_{1.092}$ as a pseudobinary system.

A material with a specific atomic structure (which could be amorphous in the case of a liquid, gas or fluid).

A phase with a fixed composition.

A phase which can vary in composition along one or more compositional vectors. In our study, ferropericlase, bridgmanite and melt are solutions made up of two endmembers.

A solution where the enthalpy and volume change of mixing are exactly zero.

A collection of one or more phases.

An assemblage where the phase proportions and compositions are such that the Gibbs free energy is minimized at the given pressure, temperature and bulk composition.

The temperature at which an assemblage of fixed pressure and composition will start to melt.

The temperature at which an assemblage of fixed pressure and composition will become completely molten.

A compositional diagram showing the first phases to crystallize from melts of given compositions. Often contoured with the liquidus temperature.

The locus of positions in P-T-composition space where two or more solid phases are in equilibrium with a liquid phase, and crystallize together (without resorption) on decreasing temperature.

A region of temperature-composition space where a solid solution and a liquid solution coexist. Bounded by a solidus and a liquidus.

The property of a substance with one mole $\left(n_{A}\right)$ of formula units of the molar composition, where $n_{A}$ is Avogadro's number $(\sim 6.022 \mathrm{e}+23)$. For example, the molar volume of periclase is the volume of one mole of $\mathrm{MgO}$ in the periclase structure.

The volume fraction of melt in a material. 
ities associated with this difference in time scales, we decouple the solution of these two steps from each other, using a first-order operator splitting scheme. Instead of solving

$$
\frac{\partial \mathbf{X}}{\partial t}+\mathbf{u} \cdot \nabla \mathbf{X}=\Gamma^{\mathbf{X}}(\mathbf{X}, p, T)
$$

where $\mathbf{X}$ is the vector of all advected quantities that are involved in the reactions, we first compute the update $\Delta \mathbf{X}_{\text {Reaction }}$ of $\mathbf{X}$ caused by melting or freezing reactions. This is done by solving a system of ordinary differential equations:

$$
\frac{\partial \mathbf{X}}{\partial t}=\Gamma^{\mathbf{X}}(\mathbf{X}, p, T)
$$

Due to this decoupling, we can choose the time step size for equation (B.2) independently of the advection problems (6) and (7). Therefore, we can choose a small time step size that allows it to accurately resolve the melting/freezing process, which means we update $\mathbf{X}$ in several iterations per advection time step.

In a second step, we obtain the update $\Delta \mathbf{X}_{\text {Advection }}$ by advecting $\mathbf{X}$ using the solution of the reaction problem

$$
\frac{\partial\left(\mathbf{X}+\Delta \mathbf{X}_{\text {Reaction }}\right)}{\partial t}+\mathbf{u} \cdot \nabla\left(\mathbf{X}+\Delta \mathbf{X}_{\text {Reaction }}\right)=0 \text {. }
$$

The time step for this advection step can be chosen much larger than for the reaction problem. The complete update of $\mathbf{X}$ for any given time step $t^{n}$ is then given as $\mathbf{X}\left(t^{n+1}\right)=\mathbf{X}\left(t^{n}\right)+\Delta \mathbf{X}_{\text {Reaction }}\left(t^{n}\right)+$ $\Delta \mathbf{X}_{\text {Advection }}\left(t^{n}\right)$.

In order to compute the reaction rates $\Gamma^{\mathbf{X}}(\mathbf{X}, p, T)$ required to solve Equation (B.2) for the different components, we use the equilibrium melt fraction (or composition) provided by the melting parametrization and assume that the reaction rate is proportional to the difference between the current porosity (or composition) in the model and the equilibrium value:

$$
\begin{aligned}
\Gamma & =\frac{(F-\phi) \rho_{f}}{\delta t_{\text {melting }}} \\
\Gamma^{s} & =\frac{\left(C_{\mathrm{eq}}^{s}-C_{s}\right)}{\delta t_{\text {melting }}} \\
\Gamma^{f} & =\frac{\left(C_{\mathrm{eq}}^{f}-C_{f}\right)}{\delta t_{\text {melting }}}
\end{aligned}
$$

Here, $F$ is the equilibrium melt fraction computed by the melting model, $\phi$ is the current porosity in the geodynamic model, $C_{\mathrm{eq}}^{s}$ is the equilibrium composition of the solid, $C_{\mathrm{eq}}^{f}$ is the equilibrium composition of the melt, and $\delta t_{\text {melting }}$ is the melting time scale, a model parameter. Since $F, C_{\text {eq }}^{s}$ and $C_{\text {eq }}^{f}$ are computed by the melting parametrization, they are set up so that they conserve bulk composition. As long as the time step for computing this reaction is substantially smaller than the melting time scale $\left(\Delta t_{\text {Reaction }} \ll \delta t_{\text {melting }}\right.$ ), this is an accurate approximation and the porosity and 


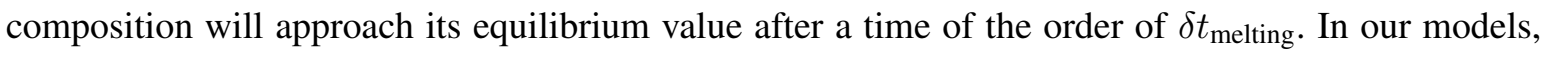
we use $\delta t_{\text {melting }}=1000 \mathrm{yrs}$. We apply the same method to the latent heat release/consumption term $\Delta \mathcal{H} \Gamma$ in Equation 5, which is directly proportional to the melting rate.

A particular challenge in this approach is the nonlinear nature of the coupling between equilibrium melt fraction, equilibrium solid composition, and equilibrium melt composition. If the analytical formulation of any of these quantities is not compatible with the geodynamic model (e.g. if the melting model contains non-differentiable kinks at the solidus that are not representable in the polynomial basis functions of the finite element model) this can lead to oscillations in melt fraction or composition of melt or solid at the boundary of the melting region. We have found that this complication can be circumvented by smoothing the equilibrium melt model around discontinuities such as the solidus conditions. While motivated by the numerical challenges this approach is comparable to having a small amount of volatiles in the melt model (see Section B2), which prevents a sharp transition from purely solid to partially molten conditions. Instead, specifically for the purpose of computing equilibrium compositions and melt fractions the model then assumes a very small amount of the fluid phase exists everywhere in the model.

\section{B2 Explicit addition of a volatile component}

To stabilize the advection of the chemicalcomposition as outlined above, we add a volatile component to the pseudobinary system, which exists only in the melt phase. Feasible volatile components in the deep Earth include $\mathrm{H}_{2} \mathrm{O}$ or $\mathrm{CO}_{2}$, neither of which are likely to exist in significant concentrations in bridgmanite or periclase at the conditions of the CMB.

We assume ideal mixing of the volatile component in the melt. Liquid and solid compositions can be calculated by modifying Equation (14):

$$
X_{\text {liq }, 1}=1-\left(\frac{1-\left(1-X_{\text {liq }, 2}\right) \exp \left(\frac{\Delta \mathcal{G}_{\text {fus }, 1}}{n_{\text {mix }, 1} R T}\right)}{\exp \left(\frac{\Delta \mathcal{G}_{\text {fus }, 0}}{n_{\text {mix }, 0} R T}\right)-\exp \left(\frac{\Delta \mathcal{G}_{\text {fus }, 1}}{n_{\text {mix }, 1} R T}\right)}\right)
$$

where Components 0,1 and 2 are the Mg-bearing, Fe-bearing and volatile components.

If the concentration of volatiles in the bulk composition is known, then the coexisting solid and melt compositions can be found by solving a quadratic: 


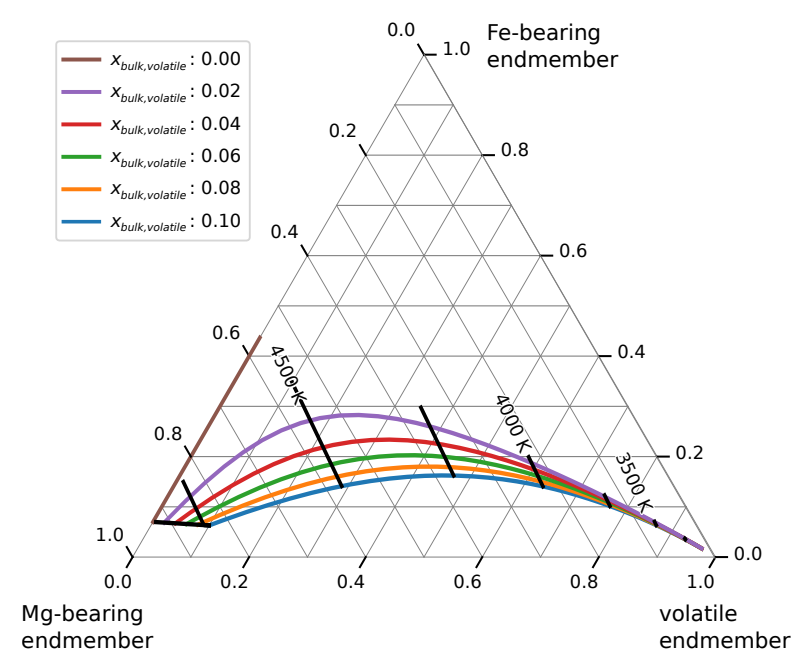

Figure A1. Melt compositions calculated using the volatile-present model at $136 \mathrm{GPa}$ for the pyrolitic bulk composition.

$$
\begin{aligned}
X_{\text {liq }, 1} & =\frac{-q_{1}+\sqrt{q_{1} q_{1}-4 q_{0} q_{2}}}{2 q_{0}} \\
X_{\text {sol }, 1} & =X_{\text {liq }, 1} p_{1} \\
q_{0} & =\left(p_{1}-p_{0}\right) \frac{p_{1}}{p_{0}} \\
q_{1} & =p_{1}\left(1-\frac{1}{p_{0}}\right)-X_{\text {bulk }, 1} \frac{\left(p_{1}-p_{0}\right)}{p_{0}}+X_{\text {bulk }, 2}\left(1-p_{1}\right) \\
q_{2} & =-X_{\text {bulk }, 1}\left(1-\frac{1}{p_{0}}\right) \\
p_{0} & =\exp \left(\frac{\Delta \mathcal{G}_{\text {fus }, 0}}{n_{\text {mix }, 0} R T}\right) \\
p_{1} & =\exp \left(\frac{\Delta \mathcal{G}_{\text {fus }, 1}}{n_{\text {mix }, 1} R T}\right)
\end{aligned}
$$

In our models, we fix the volatile concentration $X_{\text {bulk,2 }}=100 \mathrm{ppm}$, which does not significantly affect the model dynamics, but has advantages for solving the equations numerically (see Section 2.1.2).

\section{APPENDIX C: EQUATION OF STATE}

It is desirable in geodynamics simulations for material properties to be explicit in pressure and temperature (toállow for rapid evaluation during the simulation) and self-consistent (density, compressibility, thermal expansivity and heat capacity should be derivatives of the same thermodynamic potential). Unfortunately, the equations of state used by Stixrude \& Lithgow-Bertelloni (2011) and Boukaré et al. (2015) are explicit in volume and temperature. We therefore want to clone (as close as possible) those 
equations of state with a more convenient form. In this study, we use a slightly modified form of Holland and Powell's "Modified Tait" equation of state (Holland \& Powell, 2011), which has been used to model the thermodynamic properties of high pressure phases (Holland et al., 2013a).

The solid equation of state for each mineral endmember is defined by the following equations for the Gibbs free energy $(\mathcal{G}(P, T))$ :

$$
\mathcal{G}(P, T)=\mathcal{G}\left(P_{\text {ref }}, T\right)+\int_{P_{\text {ref }}}^{P} V d P
$$

where the first term provides the Gibbs free energy at the reference pressure:

$$
\begin{aligned}
\mathcal{G}\left(P_{\text {ref }}, T\right) & =\mathcal{H}\left(P_{\text {ref }}, T_{\text {ref }}\right)+\int_{T_{\text {ref }}}^{T} C_{P}\left(P_{\text {ref }}, T\right) d T-T S\left(P_{\text {ref }}, T\right) \\
S\left(P_{\text {ref }}, T\right) & =S\left(P_{\text {ref }}, T_{\text {ref }}\right)+\int_{T_{\text {ref }}}^{T} \frac{C_{P}\left(P_{\text {ref }}, T\right)}{T} d T \\
C_{P}\left(P_{\text {ref }}, T\right) & =C_{0}+C_{1} T+C_{2} T^{-2}+C_{3} T^{-0.5}
\end{aligned}
$$

$\mathcal{H}\left(P_{\text {ref }}, T_{\text {ref }}\right), S\left(P_{\text {ref }}, T_{\text {ref }}\right)$ and the parameters $C_{i}$ are the reference temperature enthalpy, entropy and

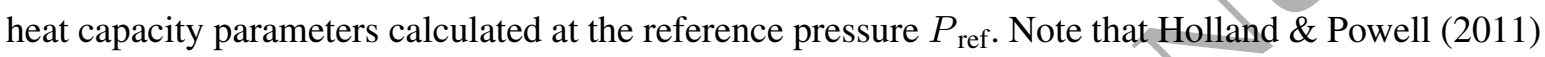
fixed the reference pressure at 1 bar (i.e. atmospheric pressure) because that is where we have the best constraints on the heat capacity. However, high temperature behaviour of the equation of state is improved by shifting the reference pressure and modifying the enthalpy, entropy and heat capacity parameters accordingly (Appendix C1). The second term in Equation C.1 gives the change in Gibbs free energy with pressure at the temperature of interest:

$$
\begin{aligned}
& \left.\int_{P_{\text {ref }}}^{P} V d P=V_{0}\left((1-a)\left(P-P_{\text {ref }}\right)+a \frac{\left(1+b\left(P_{\text {ref }}-P_{\mathrm{tr}}\right)\right)^{1-c}-\left(1+b\left(P-P_{\mathrm{tr}}\right)\right)^{1-c}}{b(c-1)}\right) \text { C.5 }\right) \\
& a=\left(1+K_{0}^{\prime}\right) /\left(1+K_{0}^{\prime}+K_{0} K_{0}^{\prime \prime}\right) \\
& b=K_{0}^{\prime} / K_{0}-K_{0}^{\prime \prime} /\left(1+K_{0}^{\prime}\right) \\
& c=\left(1+K_{0}^{\prime}+K_{0} K_{0}^{\prime \prime}\right) /\left(K_{0}^{\prime} K_{0}^{\prime}+K_{0}^{\prime}-K_{0} K_{0}^{\prime \prime}\right) \\
& P_{\mathrm{tr}}(T)=P_{\mathrm{th}}(T)-P_{\mathrm{th}}\left(T_{0}\right) \\
& P_{\mathrm{th}}(T)=\frac{\alpha_{0} K_{0}}{\xi\left(T_{0}\right)} E_{\mathrm{th}} \\
& E_{\text {th }}(T)=3 n R T_{\text {ein }}\left(0.5+1 /\left(\exp \left(T_{\text {ein }} / T\right)-1\right)\right) \\
& \xi(T)=3 n R\left(x^{2} \exp (x) /(\exp (x)-1)^{2}\right) \\
& x(T)=T_{\text {ein }} / T
\end{aligned}
$$

where $V_{0}, K_{0}, K_{0}^{\prime}, K_{0}^{\prime \prime}$ and $\alpha_{0}$ are the volume, isothermal bulk modulus and its first two pressure derivatives, and the thermal expansivity at $0 \mathrm{~Pa}$ and a fixed reference temperature $(298.15 \mathrm{~K}) . T_{\text {ein }}$ is the Einstein temperature used to calculate the change in volume away from the reference temperature. 
Table A2. Material constants used in the parametrization of solid and melt endmembers. The parameters for the equation of state are fit by least squares minimization such that the equations of state closely approximate those used by Boukaré et al. (2015). See Appendix C for the equation of state and for definitions of all of the parameters.

\begin{tabular}{|c|c|c|c|c|c|c|}
\hline Parameter & $\begin{array}{r}\text { Mg-bridgmanite } \\
\text { (mbdg) }\end{array}$ & $\begin{array}{r}\text { Fe-bridgmanite } \\
\text { (fbdg) }\end{array}$ & $\begin{array}{l}\text { Periclase } \\
\text { (per) }\end{array}$ & $\begin{array}{l}\text { Wüstite } \\
\text { (wus) }\end{array}$ & Mg-bearing melt & Fe-bearing melt \\
\hline formula & $\mathrm{MgSiO}_{3}$ & $\mathrm{FeSiO}_{3}$ & $\mathrm{MgO}$ & $\mathrm{FeO}$ & $\mathrm{Mg}_{0.581} \mathrm{Si}_{0.419} \mathrm{O}_{1.419}$ & $\mathrm{Fe}_{0.908} \mathrm{Si}_{0.092} \mathrm{O}_{1.092}$ \\
\hline $\mathrm{n}$ & 5 & 5 & 2 & 2 & 2.419 & \\
\hline$P_{\text {ref }}(\mathrm{Pa})$ & $1 e+11$ & $1 e+11$ & $1 e+11$ & $1 e+11$ & $1 e+11$ & \\
\hline mass $(\mathrm{kg} / \mathrm{mol})$ & 0.100389 & 0.131929 & 0.0403044 & 0.0718444 & 0.0485922 & \\
\hline$T_{\text {ref }}(\mathrm{K})$ & 298.15 & 298.15 & 298.15 & 298.15 & 298.15 & \\
\hline$T_{\text {ein }}(\mathrm{K})$ & 561 & 418.1 & 540.2 & 297.6 & 558.092 & 505.75 \\
\hline $\mathcal{H}\left(P_{\text {ref }}, T_{\text {ref }}\right)(\mathrm{J} / \mathrm{mol})$ & $-1.44231 \mathrm{e}+06$ & $-1.08291 \mathrm{e}+06$ & -601570 & -262240 & & -195245 \\
\hline$S\left(P_{\text {ref }}, T_{\text {ref }}\right)(\mathrm{J} / \mathrm{K} / \mathrm{mol})$ & 62.6 & 95 & 26.5 & 58.6 & & 95.0299 \\
\hline$V_{0}\left(\mathrm{~m}^{3} / \mathrm{mol}\right)$ & $2.445 \mathrm{e}-05$ & $2.534 \mathrm{e}-05$ & $1.125 \mathrm{e}-05$ & $1.206 \mathrm{e}-05$ & -05 & $1.23255 \mathrm{e}-05$ \\
\hline$K_{0}(\mathrm{~Pa})$ & $2.51 \mathrm{e}+11$ & $2.81 \mathrm{e}+11$ & $1.616 \mathrm{e}+11$ & $1.52 \mathrm{e}+11$ & $645 e+11$ & $1.66653 \mathrm{e}+11$ \\
\hline$K_{0}^{\prime}$ & 4.14 & 4.14 & 3.95 & 4.9 & 4.25283 & 5.08025 \\
\hline$K_{0}^{\prime \prime}(/ \mathrm{Pa})$ & $-1.6 \mathrm{e}-11$ & $-1.6 \mathrm{e}-11$ & $-2.4 \mathrm{e}-11$ & & $-2.13813 e-11$ & $-3.97422 \mathrm{e}-11$ \\
\hline$a_{0}(/ \mathrm{K})$ & $1.87 \mathrm{e}-05$ & $1.87 \mathrm{e}-05$ & $3.11 \mathrm{e}-05$ & $3.22 \mathrm{e}-0.5$ & $2.05727 \mathrm{e}-05$ & $2.96143 \mathrm{e}-05$ \\
\hline$C_{0}(\mathrm{~J} / \mathrm{K} / \mathrm{mol})$ & 161.5 & 139.5 & & 52 & 79.53 & 79.53 \\
\hline$C_{1}\left(\mathrm{~J} / \mathrm{K}^{2} / \mathrm{mol}\right)$ & -0.003317 & 0.006362 & & 0.003362 & -0.002419 & -0.002419 \\
\hline$C_{2}(\mathrm{JK} / \mathrm{mol})$ & $-3.575 e+06$ & $-4.139 e+06$ & -05 & $-1.195 \mathrm{e}+06$ & $-1.617 \mathrm{e}+06$ & $-1.617 \mathrm{e}+06$ \\
\hline$C_{3}\left(\mathrm{JK}^{-1 / 2} / \mathrm{mol}\right)$ & -1113 & -4648 & -593 & 25.51 & -562.2 & -562.2 \\
\hline
\end{tabular}

$P_{\mathrm{tr}}$ is the relative thermal pressure. $E_{\mathrm{th}}$ and $P_{\text {th }}$ are the thermal energy and pressure calculated using the Einstein model of heat capacity, but in this equation of state they are used only to provide a functional form for $\alpha K_{T}$. All material constants necessary for the formulas above are listed in Table A2.

\section{C1 Limitations of the Equation of State}

Two criticisms that have been levelled at Holland and Powell's "Modified Tait" equation of state (Holland \& Powell, 2011), which we use in this study, are that the thermal pressure is a function only of temperature (i.e. lines of constant volume are separated by a constant pressure, see equations (C.9) and (C.10)), and that the reference isobaric heat capacity curve is a polynomial parameterized at room pressure, which is unable to account for rapid increases in $C_{P}$ at high temperature. The first criticism is not important for this study, but the second can lead to very low, negative (or even undefined) 
heat capacities at high temperatures and pressures. To fix this, we shift the reference pressure for the isobaric heat capacity curve from $0.1 \mathrm{kPa}$ to $100 \mathrm{GPa}$ and reparameterize the curve by taking into account the integrated effect of pressure on $C_{P}$.

\section{APPENDIX D: EXAMPLE: THE EFFECT OF ALUMINUM ON SOLID-MELT PARTITIONING}

Let us consider a model atomic pyrolite composition in the CFMASO system: $\mathrm{Ca}_{1.3} \mathrm{Fe}_{2.4} \mathrm{Mg}_{20.0} \mathrm{Al}_{1.9} \mathrm{Si}_{16.0} \mathrm{O}_{58.4}$.

At the base of the lower mantle, the apparent $K_{\mathrm{Fe}-\mathrm{Mg}}^{\mathrm{bdg}-\mathrm{fper}}$ in pyrolite is $\sim 0.4$ (Irifune et al., 2010). This apparent distribution coefficient includes both ferrous and ferric iron. Including also the ferric ironaluminium partitioning suggested by Nakajima et al. (2012) $\left(\mathrm{Fe}^{3+}=-0.13 \mathrm{Al}+3.1 \mathrm{Al}^{2}-0,39 \Sigma \mathrm{Fe}\right)$ allows us to uniquely determine the molar fractions and compositions of the phases. These are:/bdg: $0.66\left(\mathrm{MgSiO}_{3}: 0.91, \mathrm{FeSiO}_{3}: 0.01 \mathrm{FeAlO}_{3}: 0.05 \mathrm{AlAlO}_{3}: 0.03\right)$, fper: 0.26 (MgO: 0.86, $\mathrm{FeO}: 0.14$ ), cpv: 0.05 , iron: 0.02 .

The crystal chemical effects causing the strong charge coupling in bridgmanite are unlikely to have close analogues in a silicate melt. For this reason, we might expect the presence of alumina to have only a minor effect on the partitioning of $\mathrm{Fe}$ and $\mathrm{Mg}$ between ferropericlase and melt. If this is true, the stabilization of ferric iron in aluminous bridgmanite will simultaneously reduce the iron concentration in coexisting melt, reducing the apparent $K_{\mathrm{Fe}-\mathrm{Mg}}^{\text {bdg-fper }}$.

In the baseline model, the $K_{\mathrm{Fe}-\mathrm{Mg}}^{\mathrm{fper}-\mathrm{liq}}$ for the pyrolite starting composition is $\sim 0.24$. Using this value, the melt in equilibrium with aluminous bridgmanite should have an Fe:Mg ratio of (0.14/0.86)/0.24 0.68. Compare this with the baseline model, where the melt has an Fe:Mg ratio of $\sim 0.9$. The $K_{\mathrm{Fe}-\mathrm{Mg}}^{\text {sol-liq }}$ will therefore be increased to 0.17 . Making the assumption that the silica content is about $30 \mathrm{~mol} \%$ (Nomura et al., 2011) and assuming negligible $\mathrm{Al}$ in the melt, the melt composition at the pyrolite solidus is $\mathrm{Mg}_{0.41} \mathrm{Fe}_{0.27} \mathrm{Si}_{0.32} \mathrm{O}_{1.32}$ (on a 1-cation basis). Finally, we calculate the ratio of (Fe/( $\left.\mathrm{Mg}+\mathrm{Fe}+\mathrm{Si}\right)$ ) in the solid vs the melt (also on a 1-cation basis) as 0.23 . This remains much lower than the experimental results of $0.47 \pm 0.09$ at $120 \mathrm{GPa}$ (Andrault et al., 2012).

\section{APPENDIX E: ADDITIONAL FIGURES AND VIDEOS}

SUPPLEMENTARY VIDEO 1 Evolution of the baseline model, where melt is approximately $1000 \mathrm{~kg} / \mathrm{m}^{3}$ denser than the solid. The top panel shows the distribution of melt (background colors, scale as in Figure 6/10) and temperature (contours). The bottom panel shows the composition of the solid (with the same color scale as in Figure 11). Melt accumulates in a basal layer that grows over time. 


\section{J. Dannberg, R. Myhill, R. Gassmöller, S. Cottaar}

Supplementary Video 2 Evolution of the model where melt is approximately $60 \mathrm{~kg} / \mathrm{m}^{3}$ denser than the solid. The top panel shows the distribution of melt (background colors, scale as in Figure 6/10) and temperature (contours). The bottom panel shows the composition of the solid (with the same color scale as in Figure 11). A region of increased melt fraction develops at the base of the plume, but does not grow over time.

Supplementary Video 3 Evolution of the model where melt is approximately $100 \mathrm{~kg} / \mathrm{m}^{3}$ less dense than the solid. The top panel shows the distribution of melt (background colors, scale as in Figure 6/10) and temperature (contours). The bottom panel shows the composition of the solid (with the same color scale as in Figure 11). A stable region of partial melt forms at the top of the melting zone. 

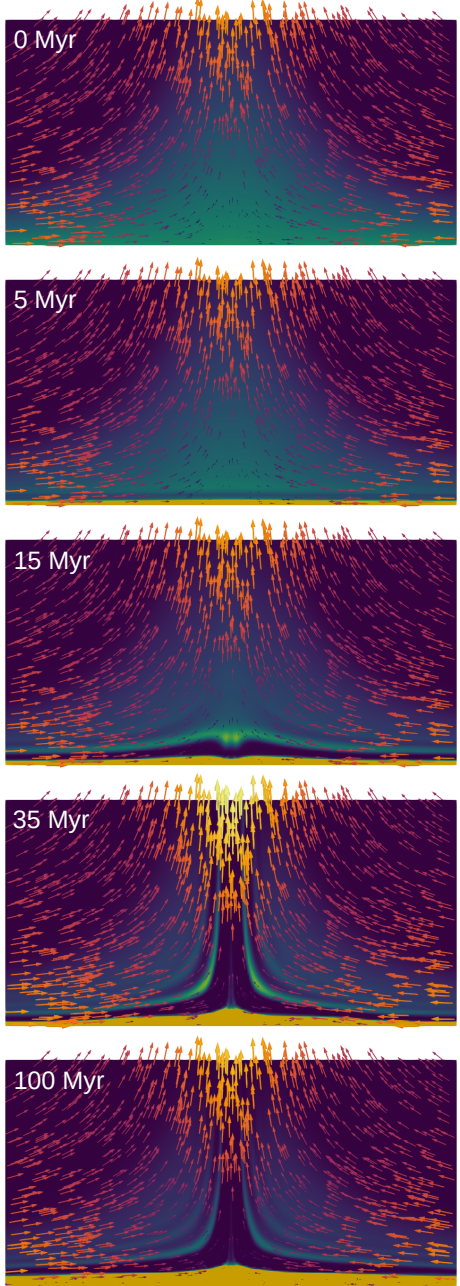

Solid velocity $(\mathrm{m} / \mathrm{yr})$

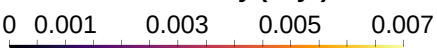

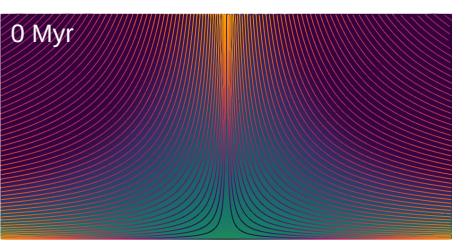
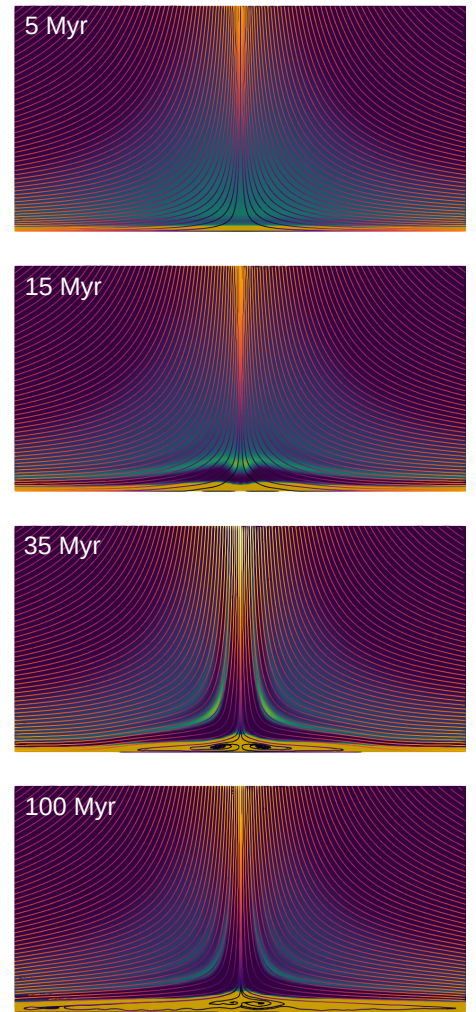

Solid velocity $(\mathrm{m} / \mathrm{yr})$

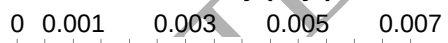

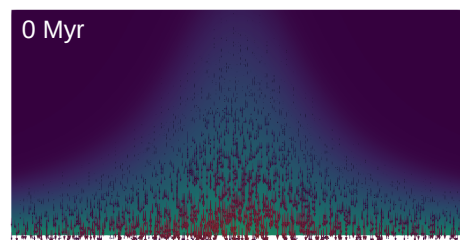
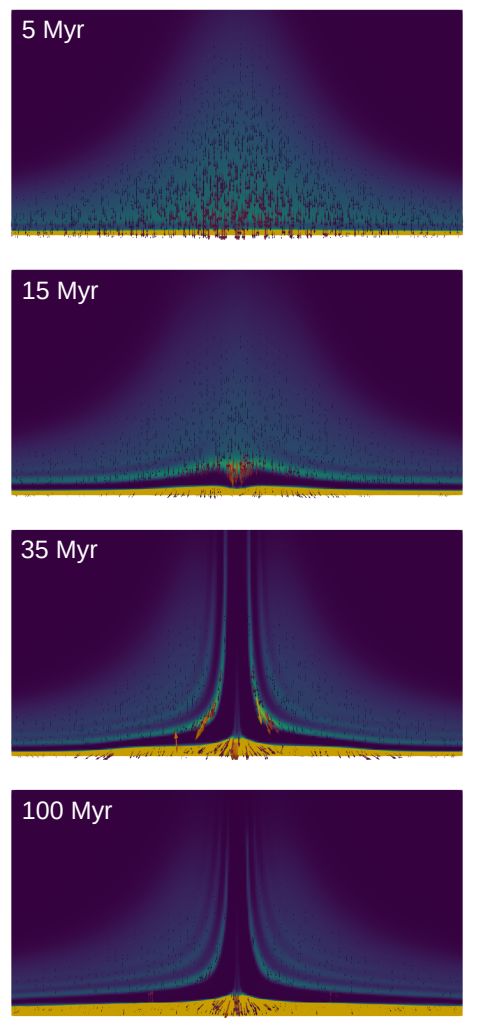

Velocity difference $(\mathrm{m} / \mathrm{yr})$

$\begin{array}{lllll}0 & 1 \mathrm{e}-4 & 3 \mathrm{e}-4 & 5 \mathrm{e}-4 & 7 \mathrm{e}-4\end{array}$

Figure A2. Evolution of the baseline model, showing the same panels as in Figure 6. The left column shows the solid velocity using arrows and the center column shows the solid velocity using streamlines, illustrating the start of internal convection in the partial melt zone about $25 \mathrm{Myr}$ after melt has started to segregate. The right column shows the velocity difference between melt and solid. Note that in the right column, the speed with which the two phases separate is an order of magnitude lower than the speed of the motion itself, and the velocity arrows are scaled by a factor of 10 compared to the right panel to make them visible. This means that a large fraction of the melt that is being generated in the partial melt region is carried upwards with the plume and freezes again, but the remaining fraction of melt that sinks down towards the CMB accumulates as a growing melt layer that is too dense to be entrained by the flow. 

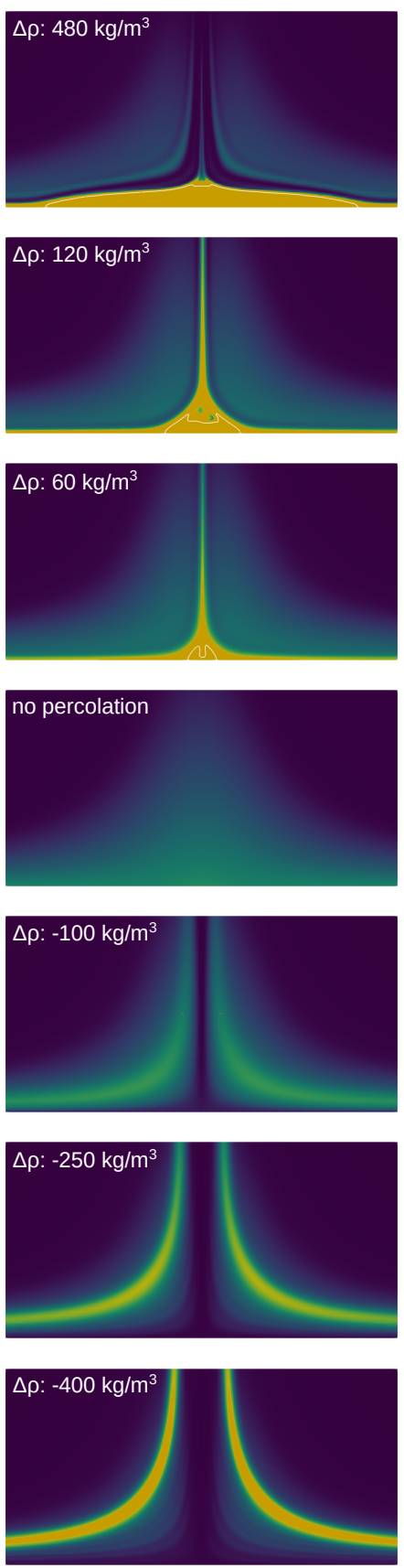

Porosity

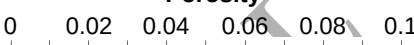

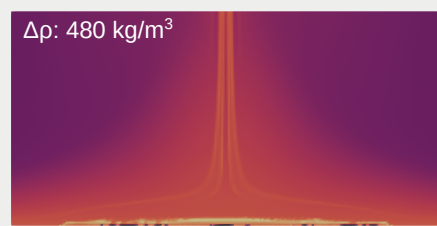
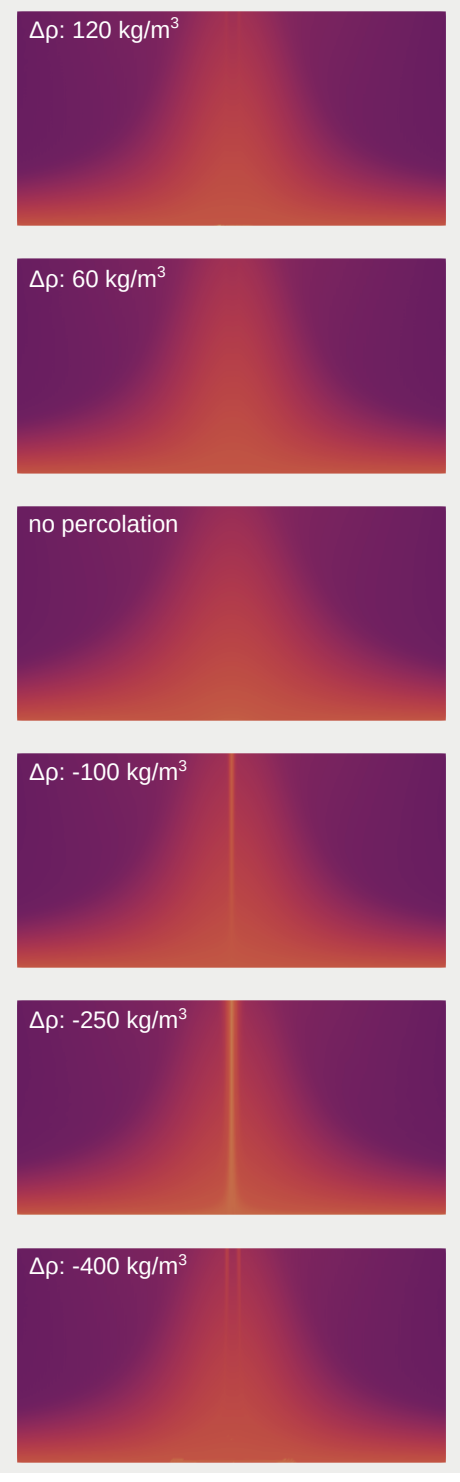

Solid density $\left(\mathrm{kg} / \mathrm{m}^{3}\right)$ $5300 \quad 5400 \quad 5500$
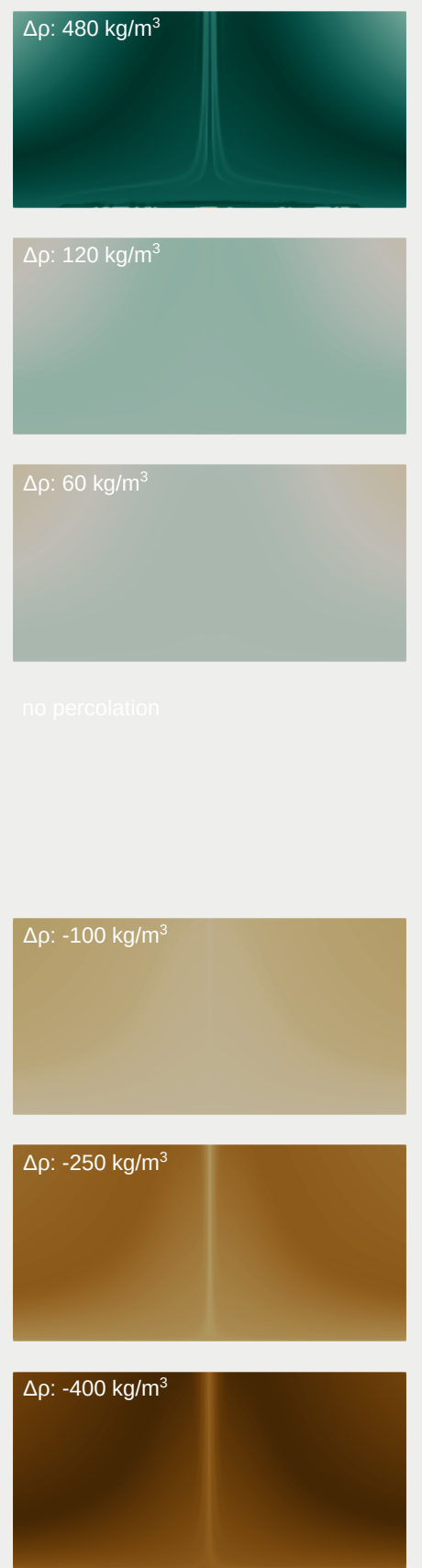

Density difference $\left(\mathrm{kg} / \mathrm{m}^{3}\right)$ $\begin{array}{llllll}-500 & -300 & -100 & 100 & 300 & 500\end{array}$

Figure A3. Morphology and density of partial melt zones for different melt densities, for a solidus reduction of $600 \mathrm{~K}$. The left column is the same as in Figure 10, the center column shows the density of the solid, and the right column shows the density difference between melt and solid. 


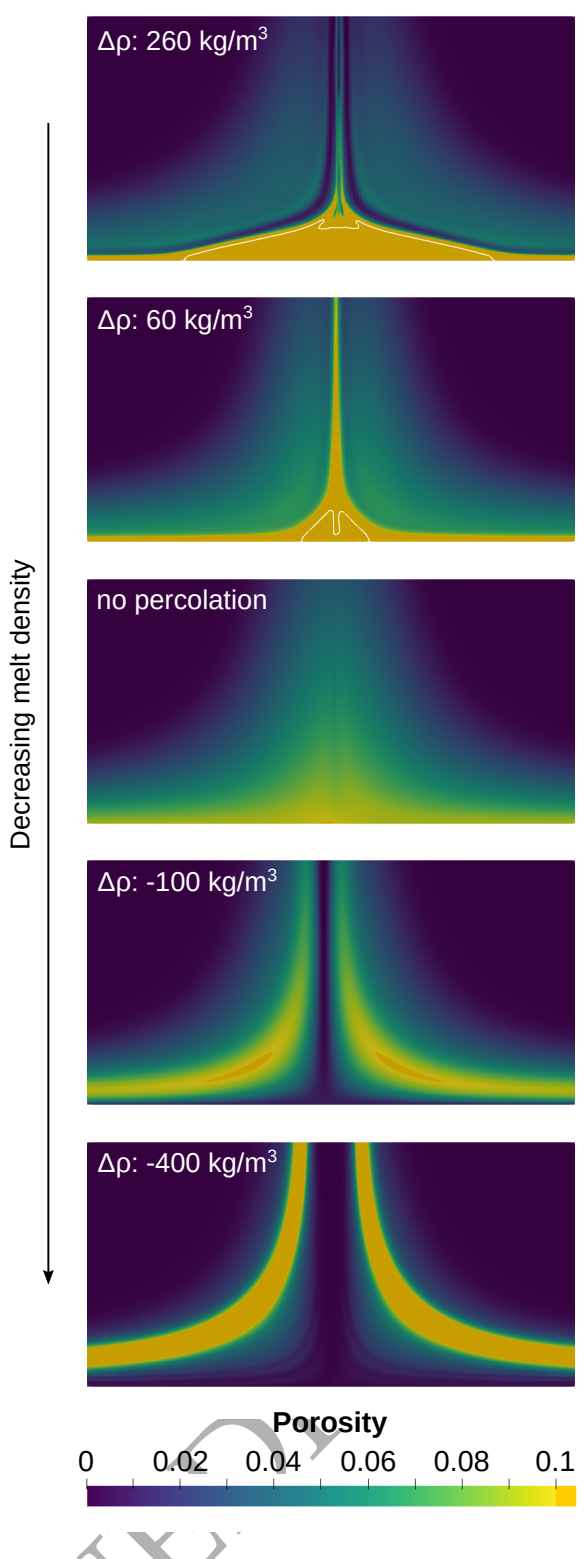

Figure A4. Morphology of partial melt zones for different melt densities, for a solidus reduction of $650 \mathrm{~K}$. All labels as in Figure 10. 